\title{
Geographic Origin Determination Of EMERALD
}

Sudarat Saeseaw, Nathan D. Renfro, Aaron C. Palke, Ziyin Sun, and Shane F. McClure

The gem trade has grown to rely on gemological laboratories to provide origin determination services for emeralds and other fine colored stones. In the laboratory, this is mostly accomplished by careful observations of inclusion characteristics, spectroscopic analysis, and trace element profile measurements by laser ablation-inductively coupled plasma-mass spectrometry (LA-ICP-MS). Inclusions and spectroscopy can often separate Colombian emeralds from other sources (although there is some overlap between Colombian, Afghan, and Chinese [Davdar] emeralds). For non-Colombian emeralds, trace element analysis by LA-ICP-MS is needed in addition to information from the stone's inclusions. The relative chemical diversity of emeralds from worldwide deposits allows confidence in origin determination in most cases. This contribution outlines the methods and criteria used at GIA for geographic origin determination for emerald.

W hen the Spanish conquistadors first brought Colombian emeralds (figures 1 and 2) onto the international market, they became a global sensation in their day. Emeralds from Central Asia and Egypt were known at the time, but the world had likely never seen emeralds of such high quality and size. Traders soon developed distribution channels that brought the Colombian material all the way from the royal courts in Europe to the powerful Moguls of India (Giuliani et al., 2000).

The nineteenth and twentieth centuries saw all of this change as new mines sprang up around the world to challenge the famed Colombian emeralds. Most notable in terms of high-quality production were Brazil, Russia, and Zambia, but smaller deposits have been uncovered in Madagascar and Ethiopia and elsewhere. As the market has evolved alongside these developments, geographic origin has come to be an important factor for fine-quality emeralds. The demand for emerald origin determination was initially driven by the proliferation of sources. However, this expansion and diversification of emerald sources has also complicated origin determination. As the number of sources grows, so does the overlap in their characteristics. The following sections will detail the

See end of article for About the Authors and Acknowledgments.

Gems \& Gemologr, Vol. 55, No. 4, pp. 614-646,

http://dx.doi.org/10.5741/GEMS.55.4.614

(C) 2019 Gemological Institute of America specific criteria used in the laboratory at GIA to make geographic origin conclusions for emeralds, as well as potential areas of overlap and how these are dealt with.

\section{In Brief}

- Emerald origin determination can be challenging due to the number of deposits and their often similar inclusion scenes.

- Emeralds can be classified as hydrothermal/metamorphic or schist-hosted based on UV-Vis-NIR spectroscopy and inclusions.

- Hydrothermal/metamorphic emeralds, including those from Colombia, have jagged fluid inclusions but can easily be separated by trace element chemistry.

- For schist-hosted emeralds, a combination of trace element chemistry and microscopic observations of inclusions is required for a conclusive origin determination.

\section{SAMPLES AND ANALYTICAL METHODS}

Emeralds included in this study are dominantly from GIA's reference collection, which was assembled over more than a decade by GIA's field gemology department. Stones in GIA's reference collection were obtained from reliable sources and collected as close to the mining source as possible; see Vertriest et al. (2019), pp. 490-511 of this issue. When necessary, the data from the reference collection was supplemented 


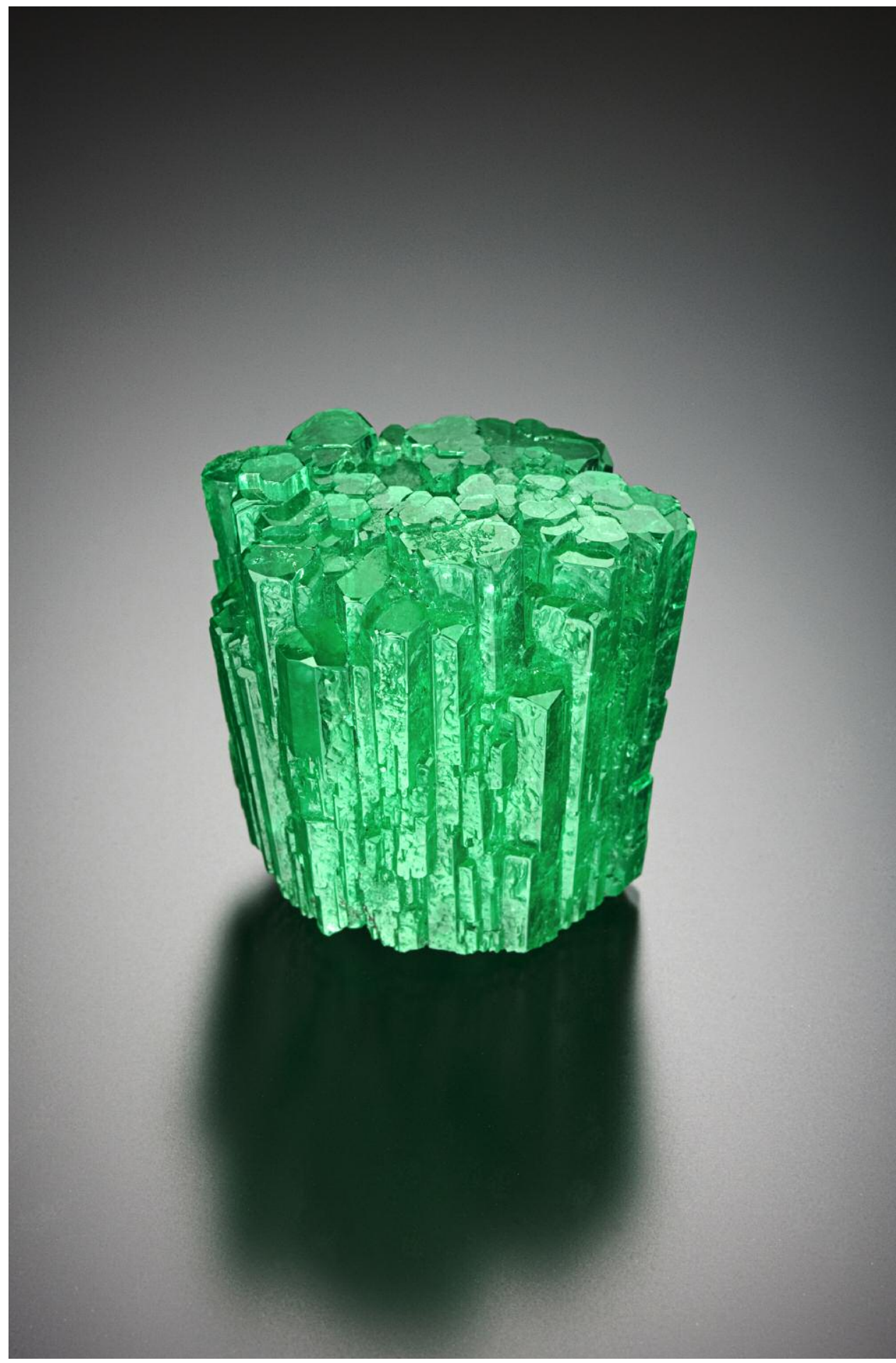

Figure 1. An $88.4 \mathrm{~g}$ emerald crystal from Coscuez, Colombia. Photo by Robert Weldon/GIA; courtesy of the Roz and Gene Meieran Collection.

by stones gathered by the authors of this study outside of the field gemology program or borrowed from GIA's museum collection. The trace element data was obtained from 298 samples total, with 36 from Zambia (25 from Kafubu and 11 from Musakashi), 34 from Colombia, 36 from Afghanistan, 22 from Mada- gascar, 64 from Russia, 49 from Brazil, 32 from Ethiopia, and 25 from China (Davdar). Emeralds from Madagascar are much less frequently encountered in the lab. Therefore, these deposits are included in the trace element section here, but their inclusions are not described for the sake of brevity and clarity. More 


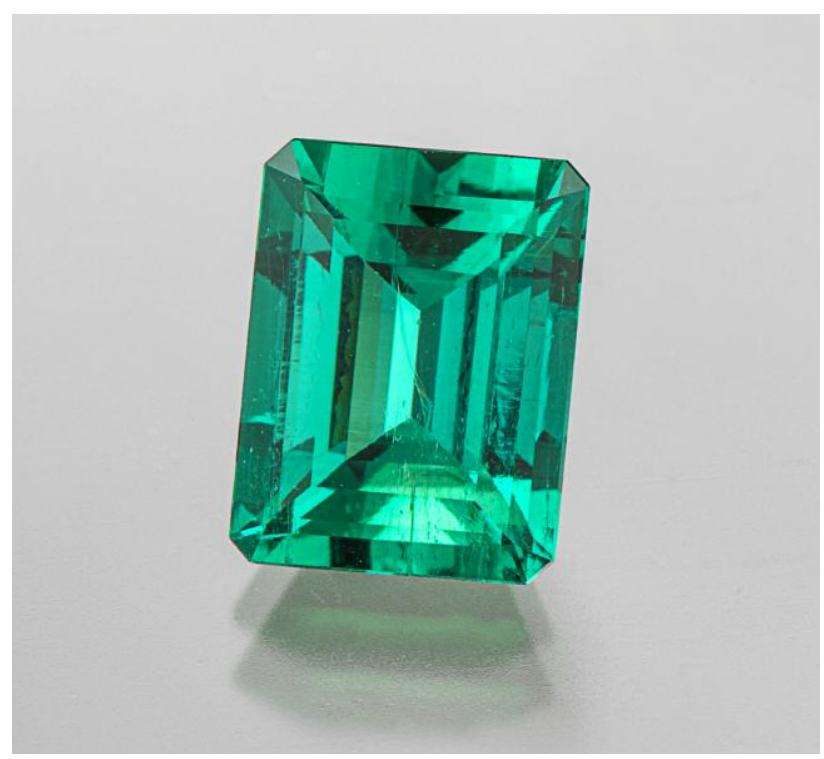

Figure 2. Colombian emerald from Chivor, $4.50 \mathrm{ct}$. Photo by Robert Weldon/GIA.

information about specific mines within these countries can be found in Vertriest et al. (2019), pp. 490511 of this issue.

Trace element chemistry was collected at GIA over the course of several years using two different LA-ICP-MS systems. The ICP-MS was either a Thermo Fisher X-Series II or iCAP Qc system, coupled to an Elemental Scientific Lasers NWR 213 laser ablation system with a frequency-quintupled Nd:YAG laser (213 nm wavelength with $4 \mathrm{~ns}$ pulse width). Ablation was carried out with $55 \mu \mathrm{m}$ spot sizes with fluence of $8-10 \mathrm{~J} / \mathrm{cm}^{2}$ and repetition rates of either 7, 10, or $20 \mathrm{~Hz} \cdot{ }^{29} \mathrm{Si}$ was used as an internal standard at $313500 \mathrm{ppm}$ using NIST 610 and 612 as external standards. Repeat analyses on samples from single locations over time have verified the consistency of the analyses with these various setups. Accuracy is estimated to be within $10-20 \%$ for most elements analyzed, based on comparisons with electron microprobe data on a small selection of samples.

Inclusions were identified, when possible, using Raman spectroscopy with a Renishaw inVia Raman microscope system. The Raman spectra of the inclusions were excited by a Stellar-REN Modu Ar-ion laser producing highly polarized light at $514 \mathrm{~nm}$ and collected at a nominal resolution of $3 \mathrm{~cm}^{-1}$ in the 2000-200 $\mathrm{cm}^{-1}$ range. In many cases, the confocal capabilities of the Raman system allowed inclusions beneath the surface to be analyzed.

UV-Vis spectra were recorded with a Hitachi U2910 spectrometer or a PerkinElmer Lambda 950 in the range of $190-1100 \mathrm{~nm}$ with a $1 \mathrm{~nm}$ spectral resolution and a scan speed of $400 \mathrm{~nm} / \mathrm{min}$. When possible, polarized spectra of oriented samples were collected to obtain o- and e-ray absorption spectra. UV-Vis-NIR spectra are presented either as relative absorbance with no units or absorption coefficient $(\alpha)$ in units of $\mathrm{cm}^{-1}$ where $\alpha=\mathrm{A} \times 2.303 / \mathrm{t}$, with $\mathrm{A}=\mathrm{ab}$ sorbance and $\mathrm{t}=$ path length in $\mathrm{cm}$.

\section{RESULTS}

UV-Vis-NIR Spectroscopy in Emerald Origin Determination. As with rubies and sapphires, emerald's geographic origin determination starts with a coarse separation into one of two groups based on their geological conditions of formation: hydrothermal/metamorphic and schist-hosted/magmatic-related /the Type II tectonic metamorphic-related and Type I tectonic magmatic-related groups from Giuliani et al., 2019, Giuliani and Groat, 2019, pp. 464-489 of this issue). This distinction also roughly corresponds to a separation between Colombian emeralds (or those emeralds that might have Colombian-like features) and essentially everything else. The hydrothermal/ metamorphic group contains emeralds from Colombia, Afghanistan, and China (Davdar), while the schisthosted/magmatic group includes emeralds from Zambia (Kafubu), Russia, Ethiopia, and Brazil, among others. In many cases, this separation can be made based on gemological properties. Hydrothermal/metamorphic emeralds often have jagged multiphase inclusions, whereas schist-hosted emeralds generally have blocky or irregular multiphase inclusions. The difference in appearance is likely related to variations in the way the fluids were originally entrapped as well as post-entrapment healing and evolution of the inclusions while the emeralds were held at high temperature and pressure before being exhumed to the earth's surface (e.g., Giuliani et al., 2019).

But advanced analytical techniques are often more reliable than relying solely on inclusions. Schisthosted emeralds generally have much higher Fe content than hydrothermal/metamorphic emeralds. This chemical distinction is most easily seen using UV-VisNIR spectroscopy. Representative UV-Vis-NIR o-ray spectra of hydrothermal/metamorphic emeralds are shown in figure 3 (top). The most prominent features in this group are the $\mathrm{Cr}^{3+}$ broad absorption bands at about 430 and $600 \mathrm{~nm}$ and the sharp $\mathrm{Cr}^{3+}$ band at around $683 \mathrm{~nm}$. A typical Colombian UV-Vis-NIR spectrum is characterized by the absence of any absorption bands in the near-IR region at wavelengths 


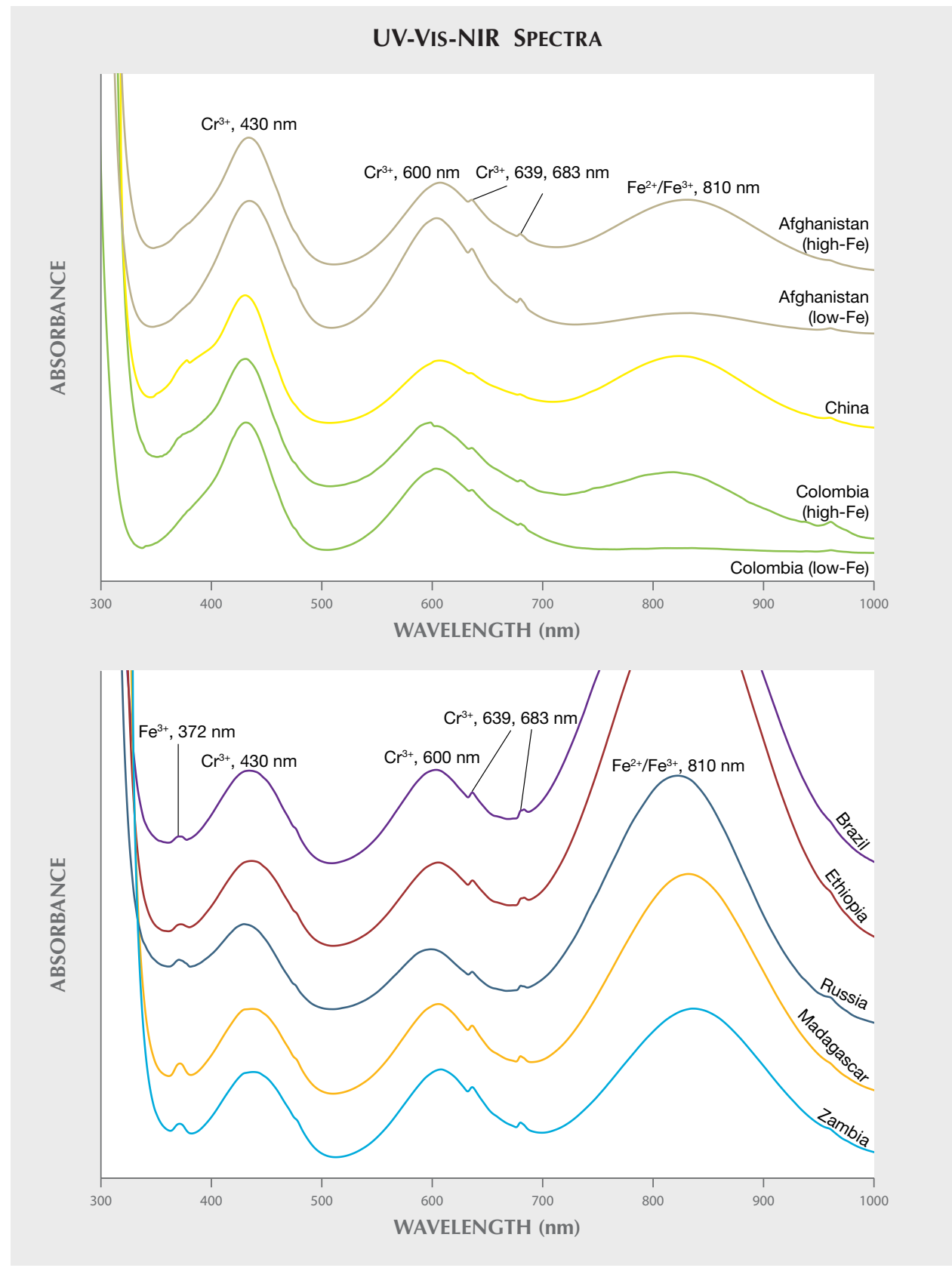

Figure 3. Top: Representative UV-Vis-NIR spectra of metamorphic/hydrothermal emeralds. The low-Fe and high-Fe Colombian emeralds have 200 and 1900 ppm Fe, respectively, while the low-Fe and high-Fe Afghan emeralds have 1100 and $2400 \mathrm{ppm} \mathrm{Fe}$, respectively. Bottom: Representative UV-VisNIR spectra of schisthosted emeralds. All spectra are o-ray spectra and have been renormalized in order to compare the relative intensities of absorption features and, hence, absolute intensities cannot be compared between spectra. The spectra are also offset by various amounts in order to facilitate comparison.

greater than $700 \mathrm{~nm}$ (bottom spectrum in figure 3, top). Other members of the hydrothermal/ metamorphic emerald group (i.e., Davdar, China, and Afghanistan), which generally have higher concentrations of Fe, usually show a noticeable to significant absorption band at $810 \mathrm{~nm}$ caused by $\mathrm{Fe}^{2+}$, possibly enhanced by nearby $\mathrm{Fe}^{3+}$. This feature has traditionally been used to separate Colombian emeralds from those from all other deposits (e.g., Saeseaw et al., 2014). However, as shown in figure 3 (top), there is some overlap between some Colombian emeralds and other members of the hydrothermal/metamorphic group. On average, Colombian emeralds have lower Fe content than stones from any other deposit. However, the few stones at the higher range of Fe content for Colombian emeralds have a noticeable $\mathrm{Fe}^{2+}$ absorption band at $810 \mathrm{~nm}$. Similarly, while Afghan emeralds tend to have higher Fe content than most Colombian stones, at their lower Fe concentration range some stones may show only a slight Fe-related absorption at $810 \mathrm{~nm}$, which could be mistaken for a classic Colombian emerald spectrum. Great care must be 
taken in interpreting UV-Vis-NIR spectra to identify possible Colombian emeralds, and multiple lines of evidence, including trace element chemistry, must be used to accurately ascertain a Colombian origin.

Due to their much higher Fe content, schist-hosted emeralds are easy to separate from Colombian and other hydrothermal/metamorphic stones based on their o-ray UV-Vis-NIR absorption spectra (figure 3, bottom). The most obvious distinction is the significantly increased intensity of the Fe-related $810 \mathrm{~nm}$ absorption band in schist-hosted emeralds. Additionally, these higher-iron emeralds also tend to have a more prominent $\mathrm{Fe}^{3+}$ absorption band at $372 \mathrm{~nm}$ than the hydrothermal/metamorphic emeralds. As with the hydrothermal/metamorphic group, making geographic origin determinations for schist-hosted emeralds requires the use of multiple lines of evidence including UV-Vis-NIR analysis, trace element chemistry, and microscopic observation of a stone's inclusions.

Microscopic Internal Inclusions. Emeralds, even topquality material, tend to be fairly heavily included. Fluid inclusions, partially healed fissures, needles, and/or solid mineral crystals are frequently encountered. Inclusions are an extremely important tool for geographic origin determination as well as separating natural and synthetic emeralds. However, there are several areas of overlap. Emeralds from some deposits may have inclusion scenes that resemble those seen in other important deposits. Some stones may lack any diagnostic inclusions, making it impossible to provide an origin opinion if there is no definitive trace element data. Gemologists often classify emerald into two broad groups based on fluid inclusions: jagged or blocky. This also corresponds roughly to the hydrothermal/metamorphic and schist-hosted classification presented above. Most fluid inclusions in emerald are multiphase, but it is often difficult to observe all the distinct phases in an inclusion using a gemological microscope. Jagged fluid inclusions usually appear to be composed of a liquid, a gas, and one or more solid phases. Sometimes there is even more than one liquid phase present as well. Regardless, when there are clearly observed solid, liquid, and gas phases present, these are typically referred to as three-phase inclusions. Blocky fluid inclusions often appear to be composed of only two phases, a liquid and a gas. However, there is often a solid phase present in these inclusions, which is hard to observe due to similarity in refractive index between the solid and fluid. Sometimes the use of cross-polarized light reveals hidden solid crystals in these fluid inclusions. Additional information about the internal features of emeralds from major world deposits can be found in the following references: Giuliani et al. (1993, 2019), Vapnik et al. (2006), Groat et al. (2008), Marshall et al. (2012), Zwaan et al. (2012), Saeseaw et al. (2014), and Vertriest and Wongrawang (2018).

Geographic Origin Determination of Hydrothermal/Metamorphic Emeralds. Colombian emeralds are the most economically important from the hydrothermal/metamorphic type of deposit, and jagged fluid inclusions are their hallmark features. Such fluid inclusions are typically elongate, with jagged sawtooth edges. Unfortunately, emeralds from other hydrothermal/metamorphic deposits such as Afghanistan and China may have similar jagged fluid inclusions. Among the mineral inclusions found in these emeralds are calcite, pyrite with various morphologies, albite, and carbonate minerals. This section will document the internal features of emeralds from Colombia, Afghanistan, and China. Emeralds from a minor deposit at Musakashi in Zambia will also be mentioned briefly at the end of this section. Further information on the inclusion scenes in emeralds from these deposits can be found in Bowersox et al. (1991), Bosshart (1991), and Saeseaw et al. (2014).

The Internal World of Colombian Emeralds. Colombian emeralds (figure 4) have long been held in high esteem for their rich green color and for the history

Figure 4. Matched pair of Colombian emeralds with no oil, approximately 10 carats total. Photo by Robert Weldon/GIA; courtesy of Amba Gem Corporation.

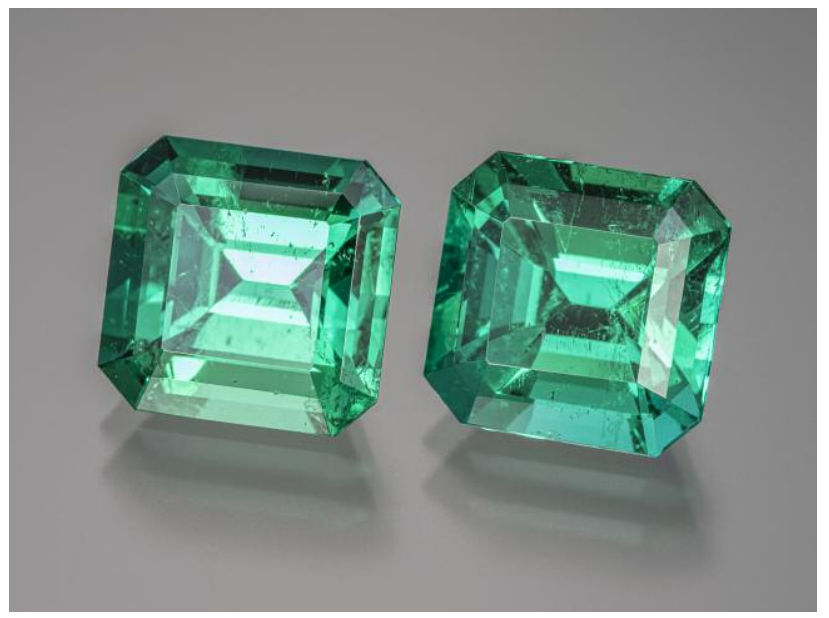




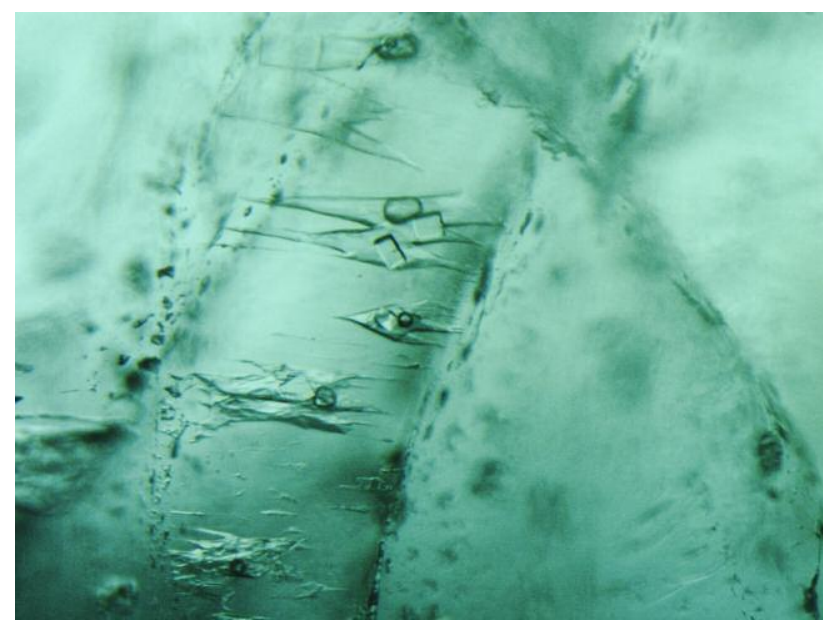

Figure 5. Small jagged inclusions in Colombian emeralds. Photomicrograph by Sudarat Saeseaw; field of view $0.9 \mathrm{~mm}$.

and legends associated with these stones. The most readily identifiable feature of Colombian emeralds are classic three-phase jagged fluid inclusions. These contain a gas bubble and a cubic crystal (typically halite and/or sylvite) and generally range in size from $100 \mu \mathrm{m}$ to $1 \mathrm{~mm}$ (figures 5 and 6). However, as mentioned above, jagged fluid inclusions can be seen in emeralds from other deposits such as Afghanistan and China (see also Saeseaw et al., 2014). Large jagged fluid inclusions (greater than about $500 \mu \mathrm{m}$ ) are unique to Colombia and can be taken as diagnostic evidence of origin. However, when only smaller jagged fluid inclusions are observed, care must be

Figure 7. Unique gota de aceite growth features in Colombian emerald. Photomicrograph by Patcharee Wongrawang; field of view $0.9 \mathrm{~mm}$.

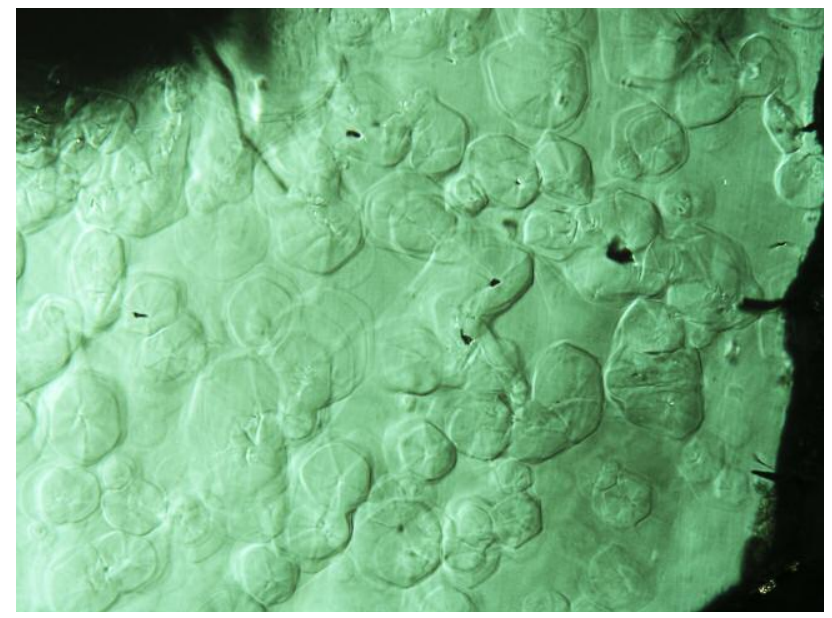

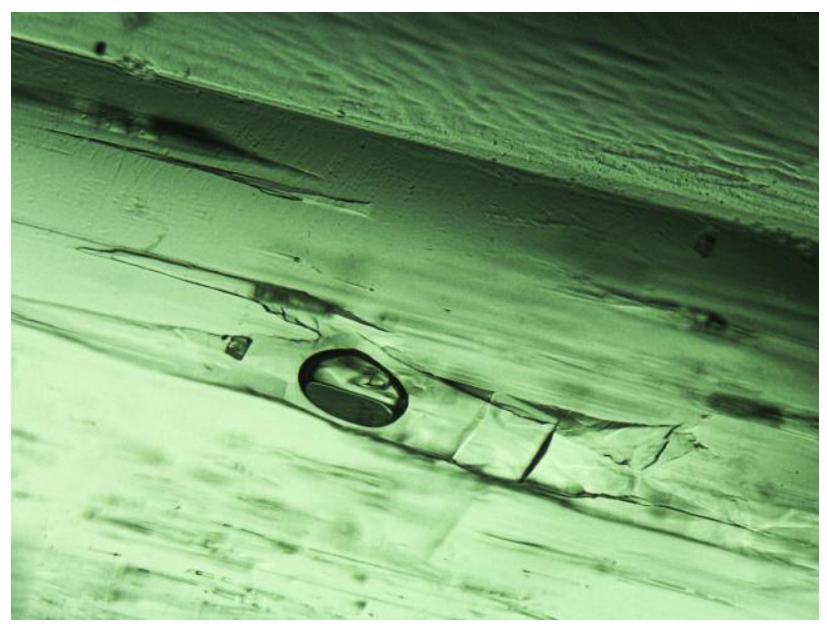

Figure 6. This large jagged multiphase inclusion is characteristic of Colombian emerald. Photomicrograph by Charuwan Khowpong; field of view $1 \mathrm{~mm}$.

taken to ascertain a stone's origin and additional supporting evidence should be sought out. Gota de aceite is a growth feature sometimes seen in Colombian emeralds that can be used as a strong indication of origin (figure 7). Similar growth features are sometimes observed in emeralds from other sources such as Zambia, but it is by far most common in emeralds from Colombia. This growth feature's name is Spanish for "drop of oil," in reference to the roiled and turbid appearance it lends. Gota de aceite grows parallel to the basal faces, often in planes that do not extend throughout the stone. Common solid inclusions in Colombian emeralds are carbonates, pyrite (figure 8),

Figure 8. Group of pyrite crystals and rhombohedral carbonate crystal in Colombian emerald. Photomicrograph by Patcharee Wongrawang; field of view $1.6 \mathrm{~mm}$.

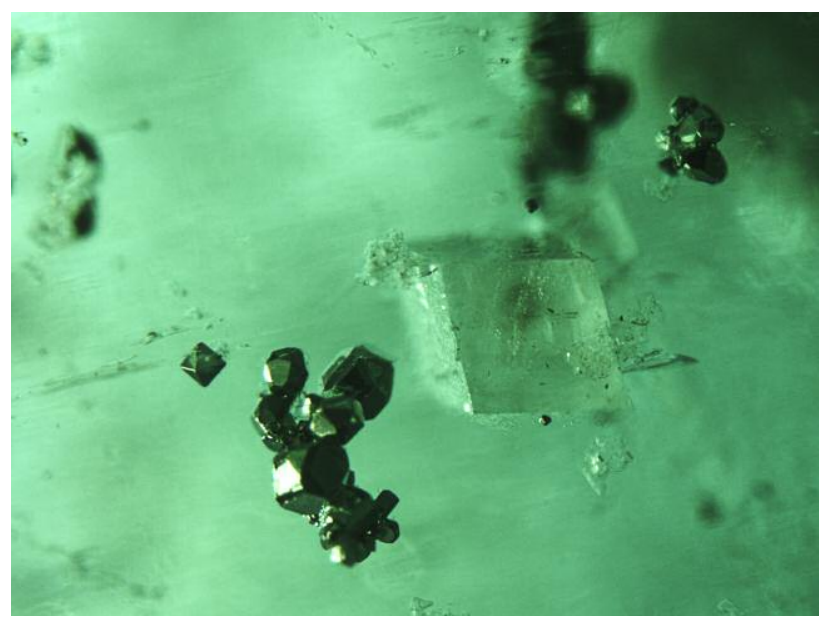




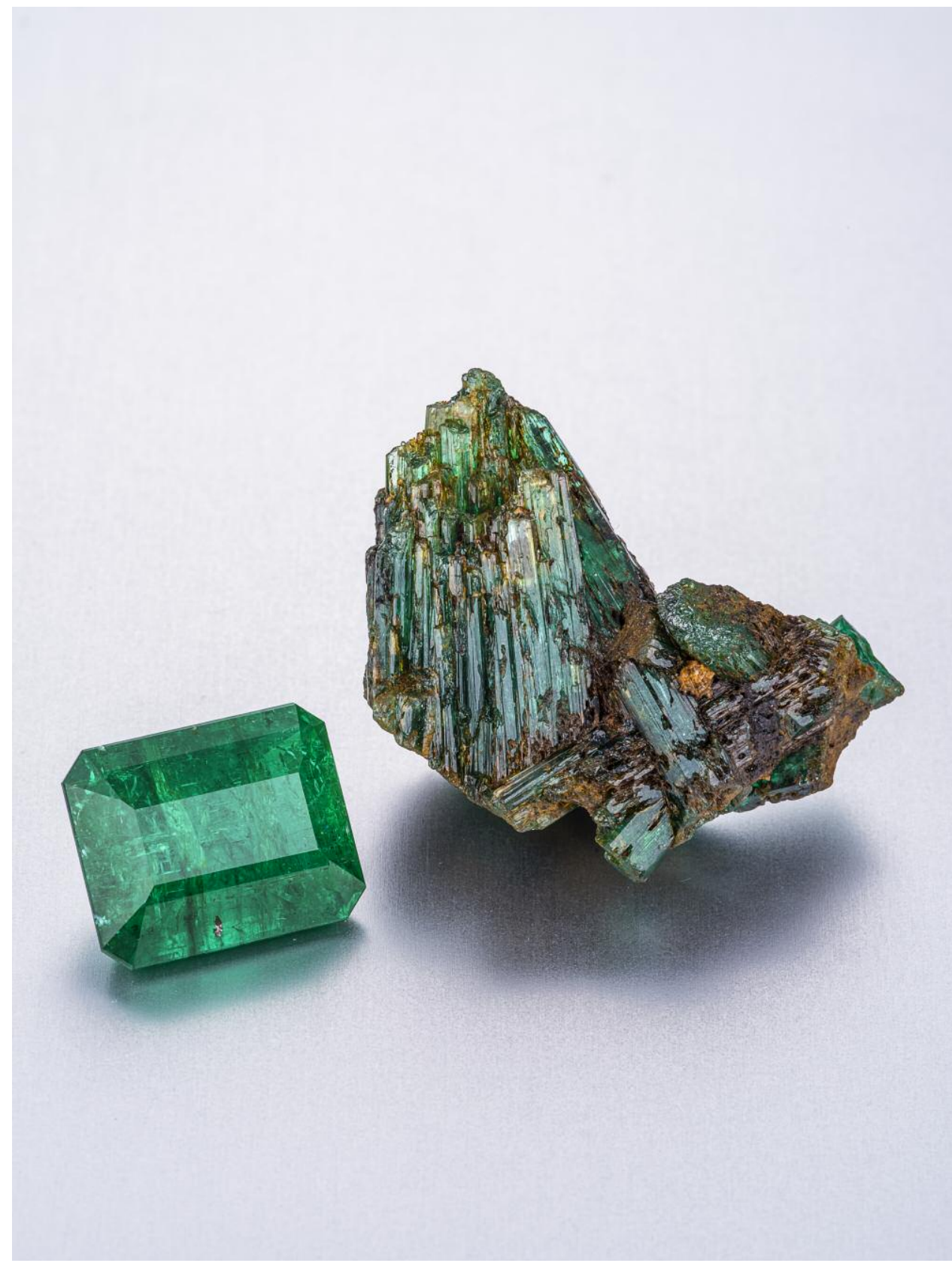

Figure 9. Emeralds from Afghanistan: a $23.43 \mathrm{ct}$ emerald-cut stone from Zarajet and an emerald crystal measuring approximately $31.7 \mathrm{~mm}$ long. Photo by Robert Weldon/GIA; courtesy of Himalayan Gems $\oplus$ Jewelry.

quartz, feldspar, and small black particles from the surrounding black shales (Giuliani et al., 2019; Giuliani and Groat, 2019, pp. 464-489 of this issue). However, most of these minerals are also found in other emerald deposits. Similar to Kashmir sapphires, Colombian emeralds also have one very rare mineral inclusion that has never been seen in emeralds from other deposits: parisite (Gübelin and Koivula, 2008). When observed, it can be considered a diagnostic indicator of Colombian origin; unfortunately, this inclusion is not frequently encountered.
The Internal World of Afghan Emeralds. While Afghan emeralds have never held the market share of their Colombian brethren, many fine stones have been produced from the mines in the Panjshir Valley (figure 9). As for their internal characteristics, multiphase fluid inclusions are the most common inclusion in Afghan emeralds. They often have an elongate, needle-like shape and host several daughter minerals (figures 10 and 11), which can distinguish them from Colombian and Chinese emeralds. Daughter minerals in fluid inclusions in emeralds are 


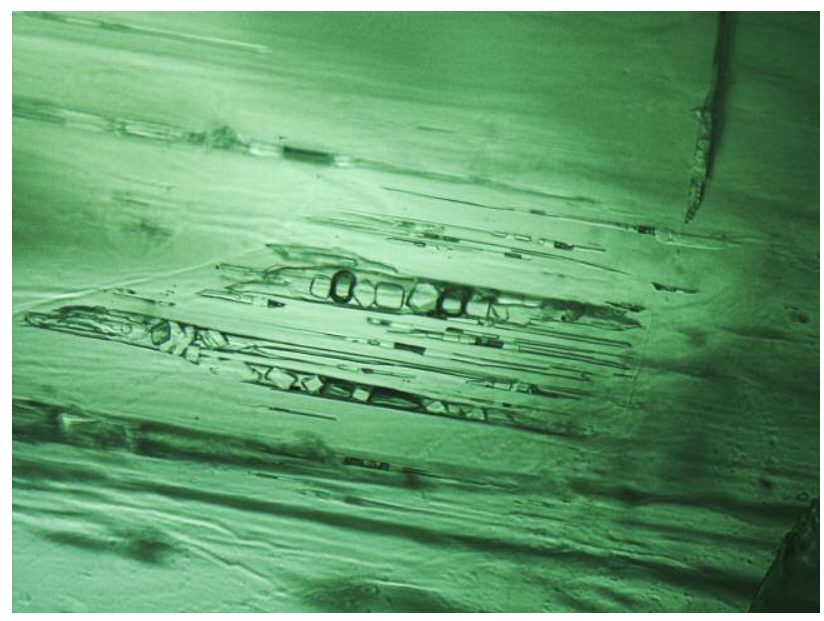

Figure 10. Elongate needle-like multiphase inclusions containing several daughter crystals and a gas bubble are typically seen in Afghan emeralds. Photomicrograph by Charuwan Khowpong; field of view $0.7 \mathrm{~mm}$.

often assumed to be halite when they have a cubic habit; however, when there are several daughter minerals, as in the inclusions in Afghan emeralds, their exact identity is often hard to determine, even with the use of confocal Raman spectroscopy. The typical inclusion scene in these emeralds from the Panjshir Valley consists of small jagged fluid inclusions (figures 12 and 13), similar to those seen in Colombian emeralds, and scarce crystalline inclusions. Solid inclusions, when present, include pyrite, limonite, beryl, carbonate minerals, and feldspar.

Figure 12. Small jagged inclusions in Afghan emerald. Photomicrograph by Nattida Ng-Pooresatien; field of view $0.7 \mathrm{~mm}$.

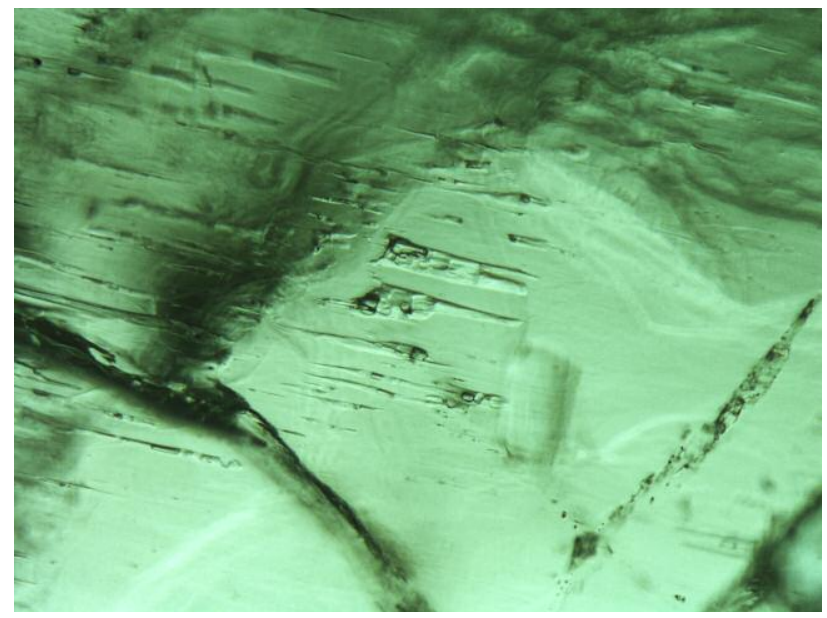

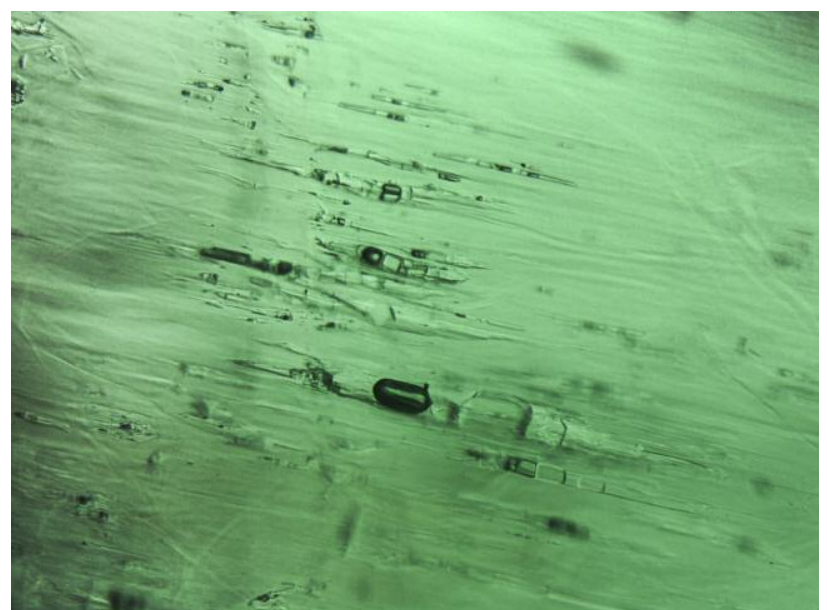

Figure 11. Needle-like multiphase inclusions lie parallel to each other in Afghan emerald. Photomicrograph by Charuwan Khowpong; field of view $0.9 \mathrm{~mm}$.

The Internal World of Chinese Emeralds. The deposit at Davdar, China, was discovered late in the twentieth century. The geology of Davdar is not well understood, but it is reported that this deposit shares some similarities with other metamorphic deposits (Giuliani et al., 2019). Fluid inclusions in these emeralds have a jagged shape and are composed of a rounded gas bubble and a cubic crystal (figures 14-17). They are often small and can resemble those seen in emeralds from Colombia and Afghanistan. While there is likely very little production from the Chinese mines

Figure 13. Irregular jagged inclusions in Afghan emerald. Photomicrograph by Nattida Ng-Pooresatien; field of view $0.9 \mathrm{~mm}$.

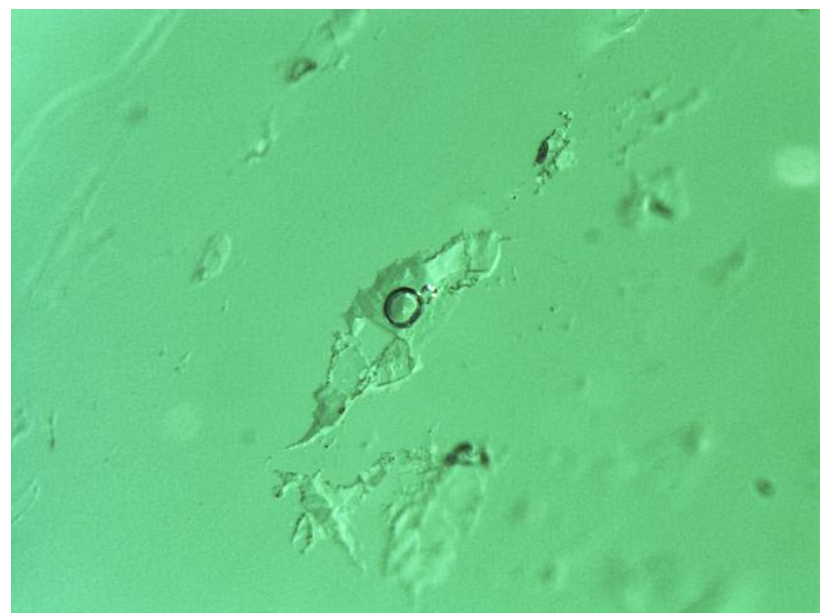




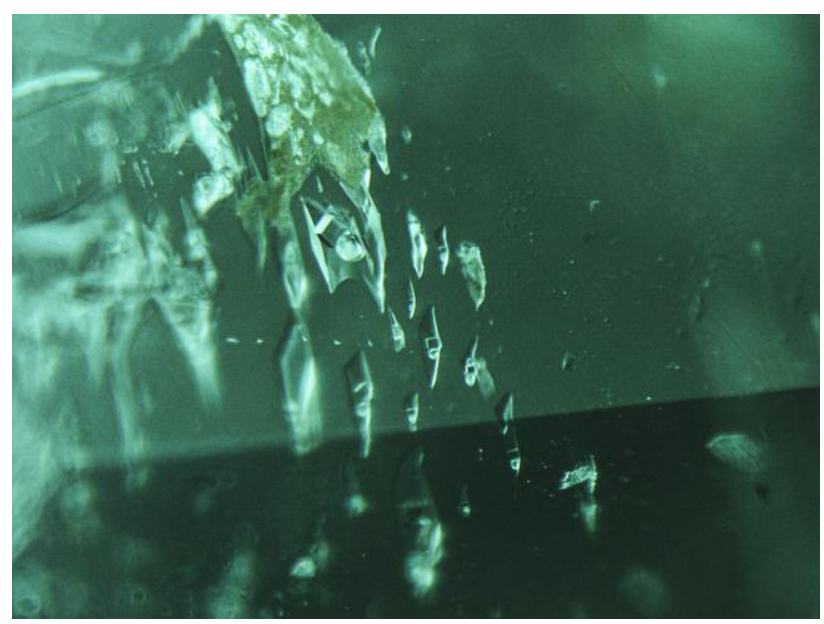

Figure 14. Jagged fluid inclusions with a transparent cubic crystal and a gas bubble in emerald from China. Photomicrograph by Sudarat Saeseaw; field of view $0.7 \mathrm{~mm}$.

reaching the market, their potential for overlap with Colombian emeralds makes it important to be aware of their identifying characteristics to avoid potential problems in origin determination.

Inclusion Scenes Gone Wrong. Many Colombian emeralds are easily identified by large jagged inclusions (figure 6) or gota de aceite growth features (figure 7). Multiphase inclusions containing numerous daughter crystals (figure 10) are considered conclusive evidence of an Afghan origin. However, it can be complicated in smaller or less-included stones where there may not be much information available to the

Figure 16. Elongate jagged inclusions in emerald from China. Photomicrograph by Nattida Ng-Pooresatien; field of view $0.7 \mathrm{~mm}$.

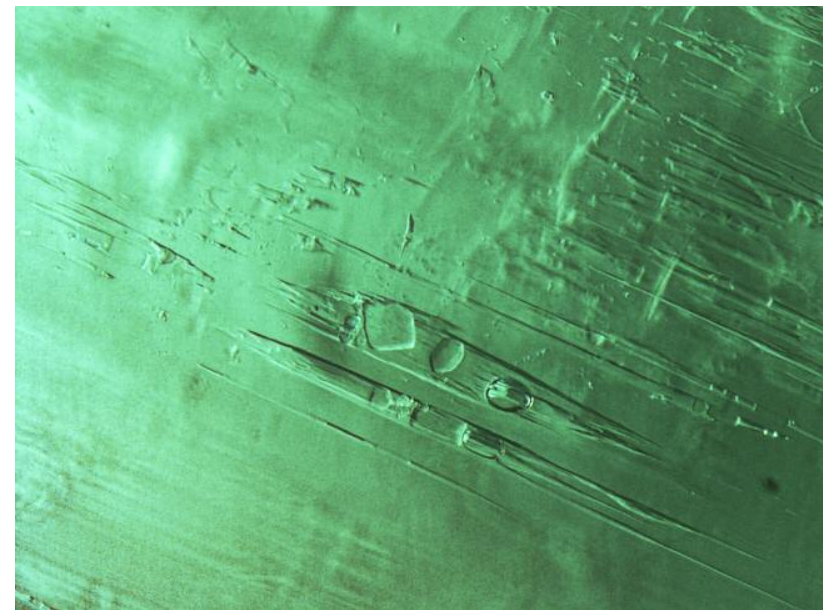

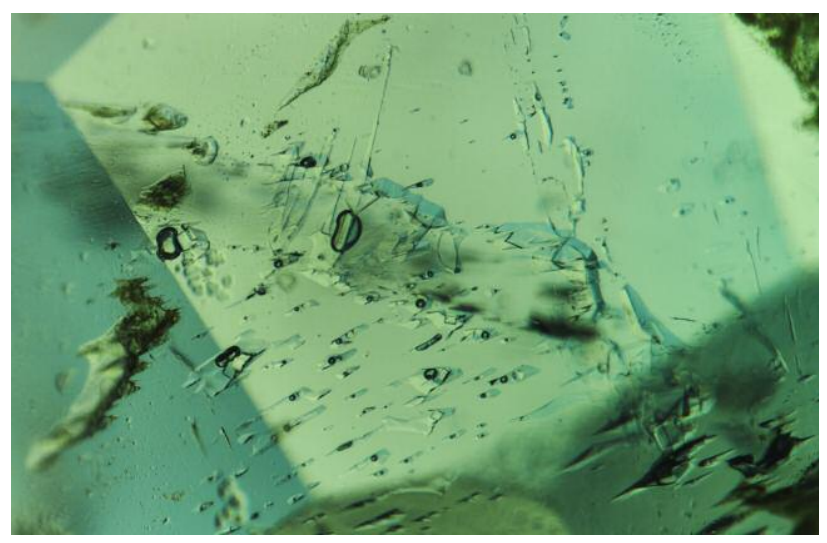

Figure 15. Jagged fluid inclusions in Chinese emerald. Photomicrograph by Charuwan Khowpong; field of view $1.05 \mathrm{~mm}$.

microscopist. For example, the inclusion scenes of two Afghan emeralds in figures 18 and 19 showed jagged edges with a rounded gas bubble and cubic crystal(s). These inclusions could easily be misinterpreted as Colombian. Similarly, emeralds from a minor deposit in Zambia at Musakashi can also have jagged three-phase inclusions similar to those seen in Colombian emeralds, making it necessary to search for further evidence (figures 20 and 21). As with the Chinese emerald deposit at Davdar, few stones have emerged from Musakashi. Nonetheless, it is important to be aware of this potential overlap in properties. UV-Vis-NIR analysis can be helpful to

Figure 17. Irregular multiphase inclusions in Chinese emerald. Photomicrograph by Nattida Ng-Pooresatien; field of view $0.7 \mathrm{~mm}$.

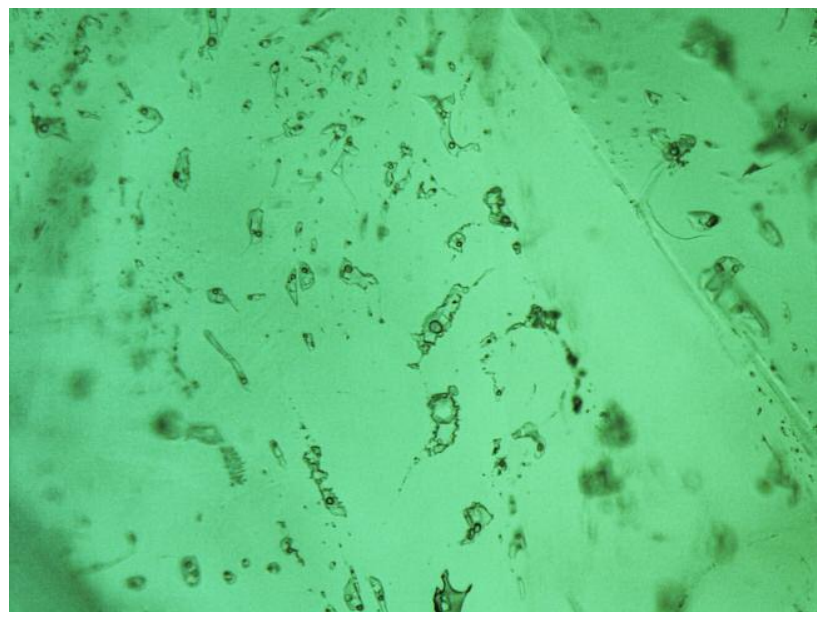




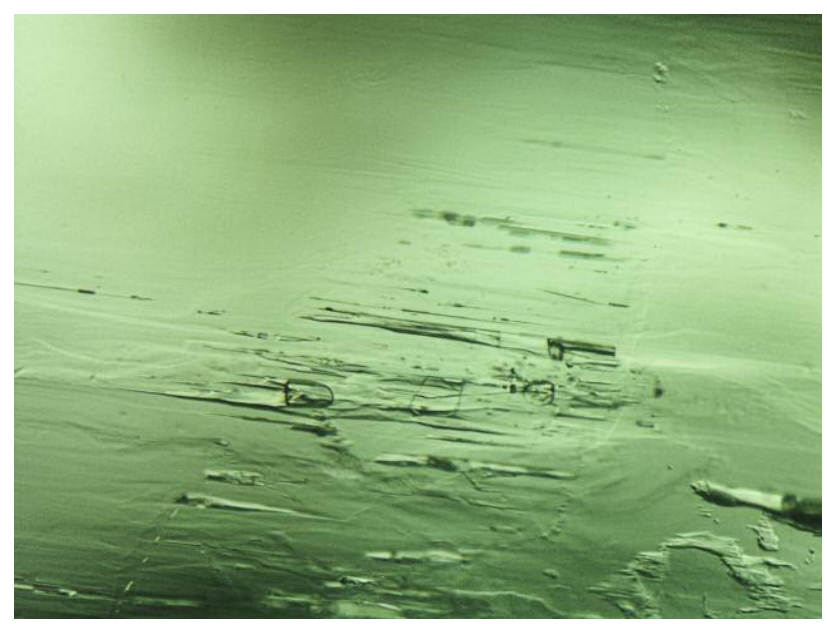

Figure 18. Jagged multiphase inclusions in an Afghan emerald appear similar to features seen in some Colombian emeralds. Photomicrograph by Nattida NgPooresatien; field of view $0.8 \mathrm{~mm}$.

separate between Colombian and Afghan, Chinese, or Musakashi emerald. Many Afghan, Chinese, and Musakashi emeralds have obvious Fe-related absorption bands distinguishing them from Colombian stones. However, there will be some overlap in the high-Fe Colombian emeralds and the low-Fe Afghan and Chinese emeralds, both of which may show minor Fe-related absorption bands. For these borderline cases, chemical analysis is needed for a conclusive result.

Geographic Origin Determination for Schist-Hosted Emeralds. Schist-hosted emerald deposits are the re-

Figure 20. Jagged three-phase fluid inclusions in an emerald from Musakashi, Zambia. Photomicrograph by Charuwan Khowpong; field of view $0.7 \mathrm{~mm}$.

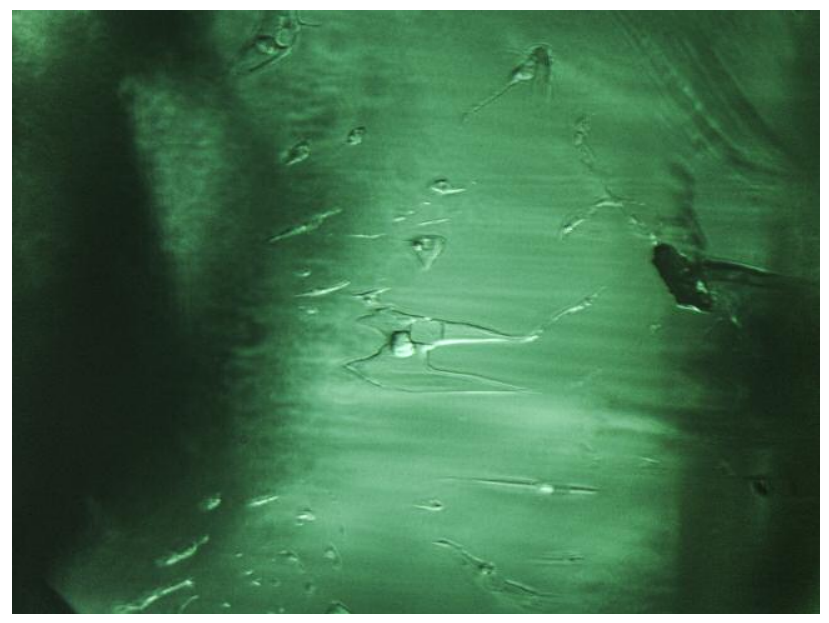

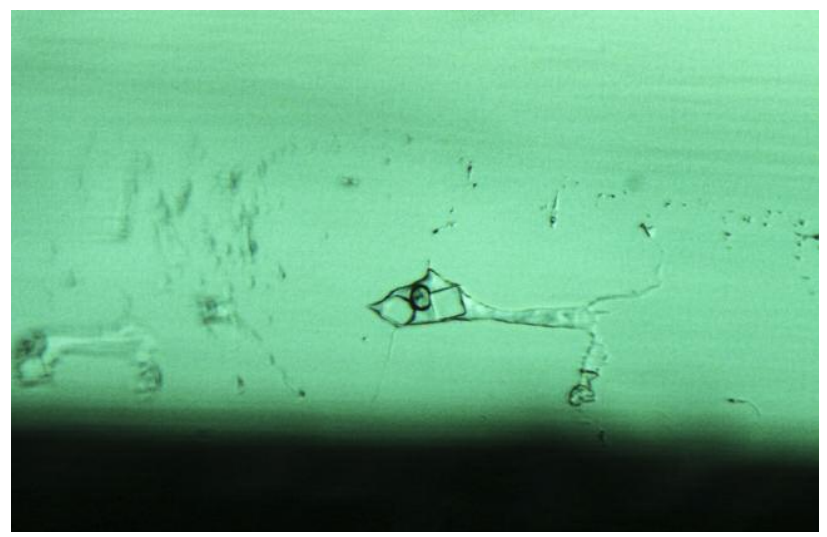

Figure 19. Irregularly shaped multiphase inclusion hosting a small gas bubble and several crystals in an Afghan emerald. Photomicrograph by GIA; field of view $0.3 \mathrm{~mm}$.

sult of magmatic processes, including pegmatitic events. Emeralds formed in these deposits through interaction of pegmatites or other magmatic bodies with mafic, ultramafic, and/or metamorphic country rocks. This type of emerald includes important sources such as Zambia (Kafubu), Brazil, Russia, and Ethiopia. These emeralds tend to have a darker green color than Colombian, Afghan, and Chinese emeralds owing to their generally higher iron content. However, some lower-iron schist-hosted emeralds, especially those from Russia, may have lighter-toned colors. Schist-hosted emeralds often have blocky fluid inclusions that can be either two-phase, three-phase,

Figure 21. Jagged three-phase fluid inclusions in an emerald from Musakashi, Zambia. Photomicrograph by Charuwan Khowpong; field of view $0.7 \mathrm{~mm}$.

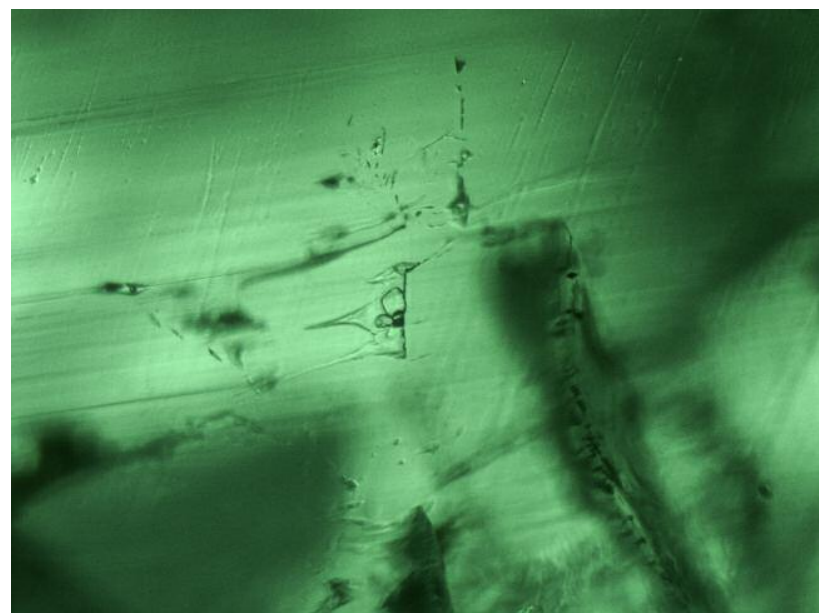




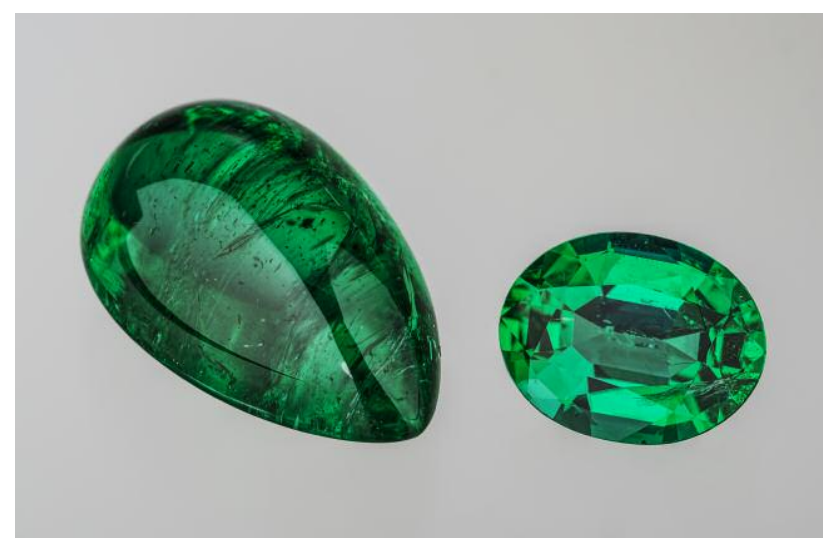

Figure 22. Zambian emeralds at $8.14 \mathrm{ct}$ (left) and 1.76 ct (right). Photo by Robert Weldon/GIA; courtesy of Mark Kaufman, Kaufman Enterprises.

or multiphase. The most common solid crystal inclusion is mica, which occurs in a variety of forms and colors. Mica can be formed before the emerald (i.e., protogenetic) or at the same time as the host crystal (syngenetic). Other mineral inclusions can also be found: dendritic black inclusions and quartz, carbonate minerals, talc, pyrite, emerald, chlorite, and spinel. The following sections will describe typical inclusion scenes for each origin. Note that emeralds from Madagascar would be included in the schist-hosted group. However, these emeralds are much less frequently encountered in the lab and so they are not included in the discussion of inclusion scenes. Nonetheless, origin determination of Madagascar emeralds will be considered later in the trace element chemistry section. Further information on the inclusion scenes in schist-hosted emeralds can be found in Cassedanne and Sauer (1984), Hänni et al. (1987), Zwaan et al. (2005), Saeseaw et al. (2014), Vertriest and Wongrawang (2018), and Palke et al. (2019a).

The Internal World of Zambian Emeralds from Kafubu. Zambian emeralds (figure 22) are found in the Kafubu area in the southern part of the historically important copper mining area known as the Copperbelt. Emerald mineralization occurs at the phlogopite-biotite contact zone between pegmatites and a talc-magnetite schist. Zambian emerald fluid inclusions are typically blocky (figure 23) or irregularly shaped (figure 24) multiphase inclusions. Mica is a common inclusion in Zambian emeralds from Kafubu, occurring with a brownish color and rounded shape (figure 25) or in pseudo-hexagonal green platelets (figure 26). Black platelets, or dendritic in-

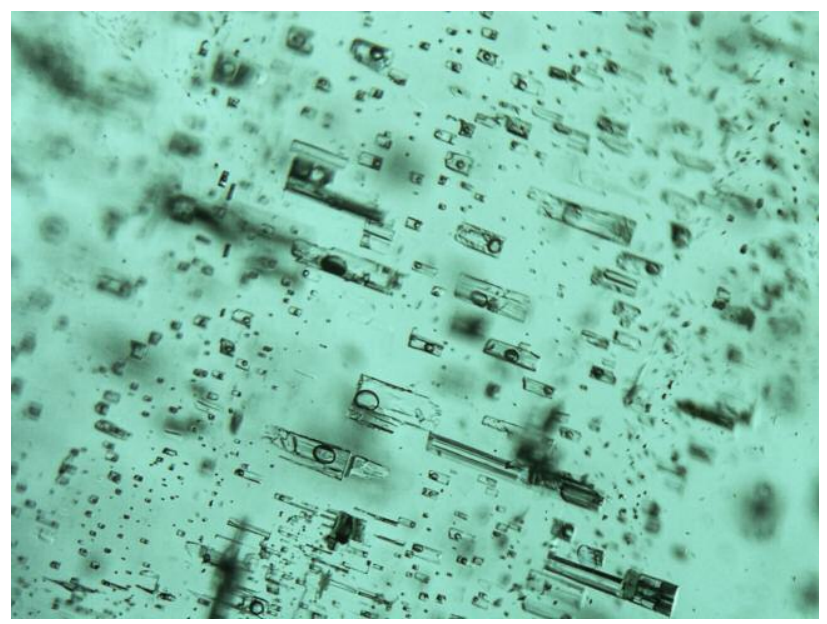

Figure 23. Blocky fluid inclusions are common in Zambian emeralds, seen perpendicular to the optic axis of the host. Photomicrograph by Nattida $\mathrm{Ng}$ Pooresatien; field of view $1.1 \mathrm{~mm}$.

clusions composed of oxide minerals such as magnetite, hematite, or ilmenite (figure 27), can be seen in Zambian and other schist-hosted emeralds. Elongate amphibole crystals are also observed occasionally in Zambian emeralds (figure 28). Other minerals such as apatite, pyrite, talc, barite, albite, and calcite have also been reported (Saeseaw et al., 2014).

The Internal World of Brazilian Emeralds. Emeralds have been discovered in several Brazilian localities including Carnaíba and Socotó (Bahia), Santa Terezinha (Goiás), and Itabira (Minas Gerais). This article will focus on production from Itabira, or the Belmont

Figure 24. Irregularly shaped multiphase inclusions in emeralds from Kafubu, Zambia, as seen parallel to the optic axis. Photomicrograph by Nattida $\mathrm{Ng}$ Pooresatien; field of view $2 \mathrm{~mm}$.

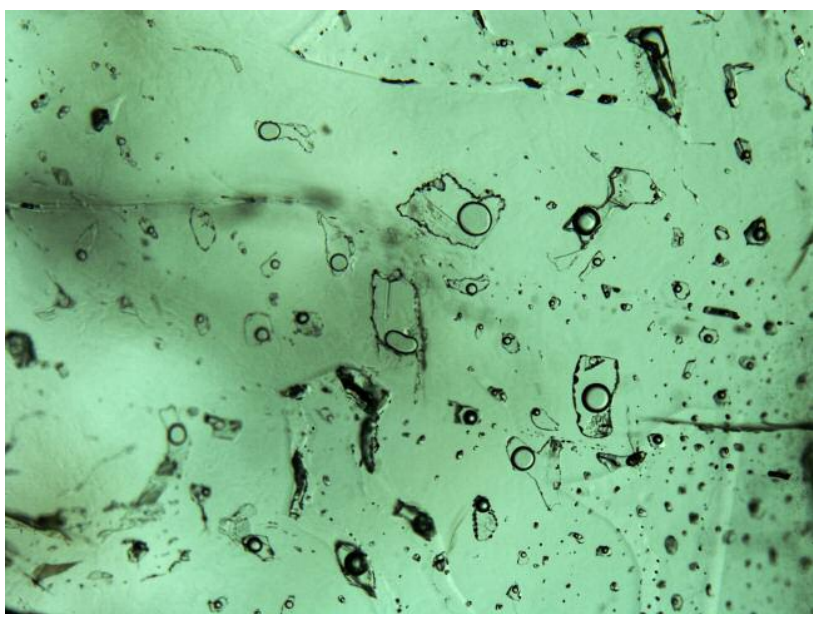




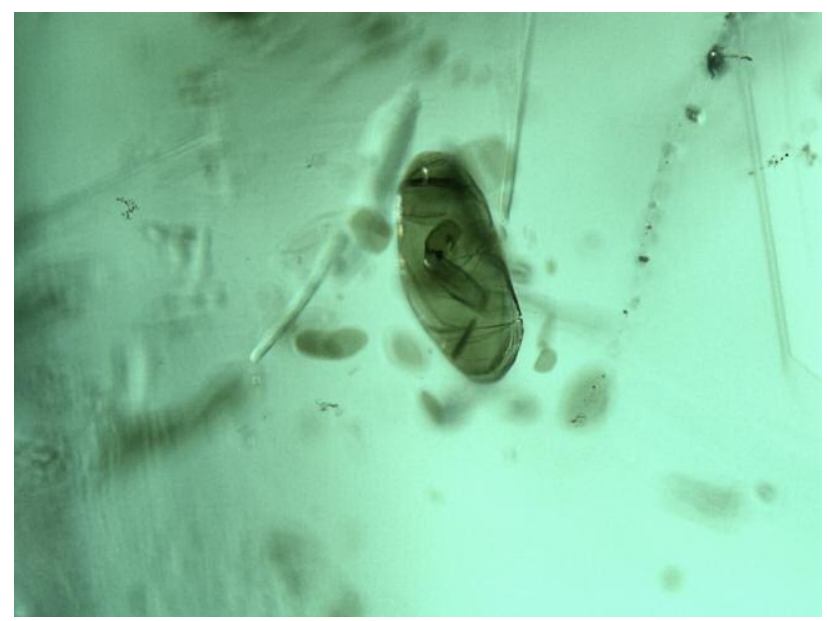

Figure 25. Brownish micas are common in Zambian emerald but can also be found in emerald from other deposits. Photomicrograph by Nattida Ng-Pooresatien; field of view $1.3 \mathrm{~mm}$.

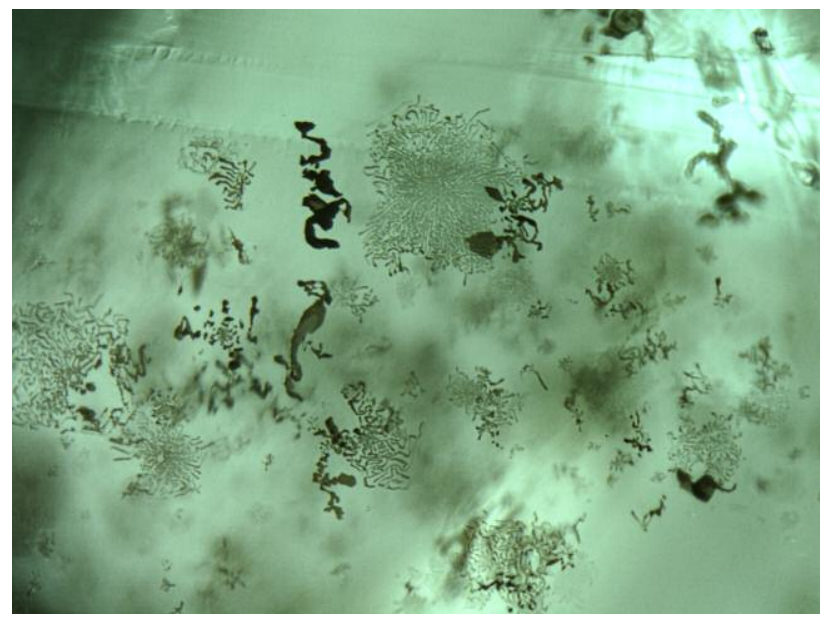

Figure 27. Opaque thin platelets showing dendritic inclusions are seen in Zambian and other schisthosted emeralds. Photomicrograph by Nattida NgPooresatien; field of view $1.0 \mathrm{~mm}$.

mine, as it is the main producer of Brazilian emerald today. Characteristic inclusions for emeralds from Belmont include blocky fluid inclusions and parallel tiny tubes described as "rain-like" (figure 29) that, if dense enough, can occasionally produce chatoyancy. The fluid inclusions typically show a blocky shape (figure 30) and may have multiple liquid/gas/solid phases apparent within (figure 31). Some irregular

Figure 29. Cloud of fine elongate tubes with various fillings form a rain-like inclusion in a Brazilian emerald. Photomicrograph by Charuwan Khowpong; field of view $1.30 \mathrm{~mm}$.

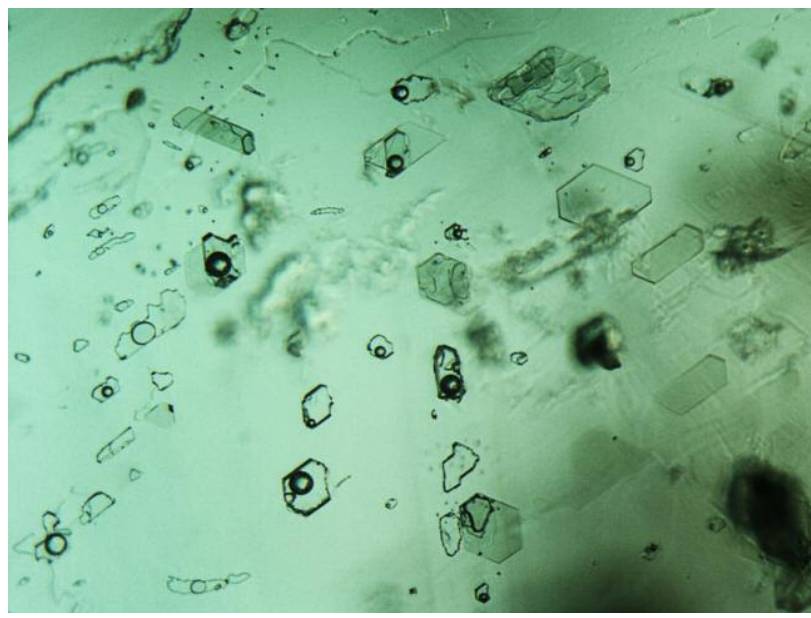

Figure 26. Pseudo-hexagonal fluid inclusions and greenish mica are common in Zambian emerald. Photomicrograph by Nattida Ng-Pooresatien; field of view $0.9 \mathrm{~mm}$.

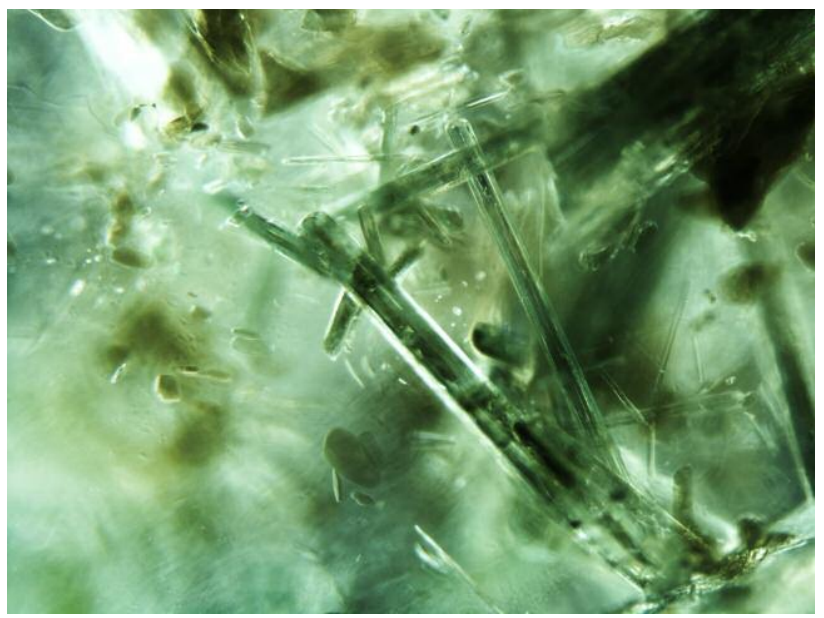

Figure 28. Greenish rod-like inclusions identified as amphibole in Zambian emerald. Photomicrograph by Nattida Ng-Pooresatien; field of view $1.6 \mathrm{~mm}$.

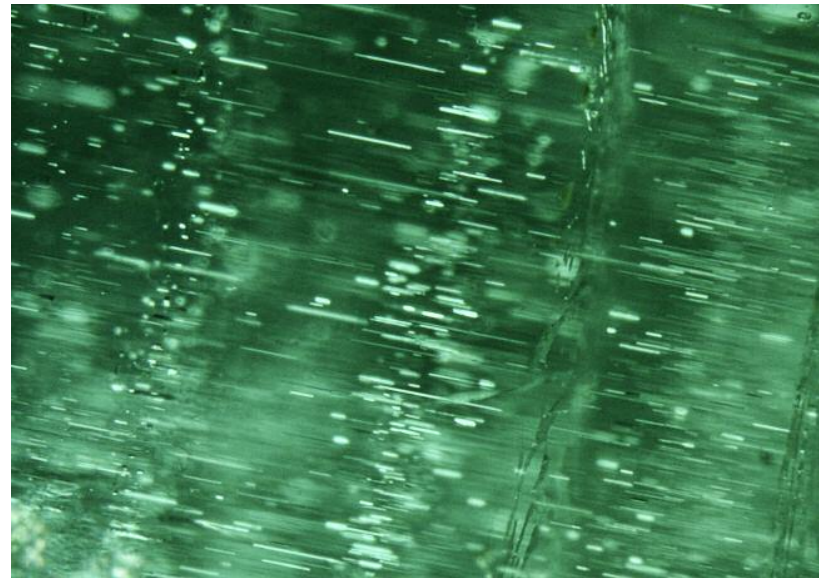




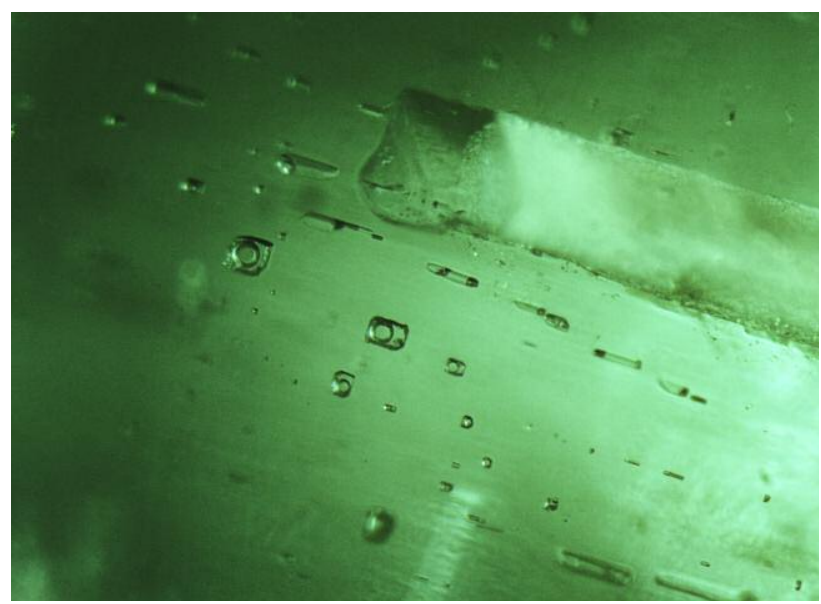

Figure 30. This Brazilian emerald contains blocky and rectangular fluid inclusions and a tube filled with aggregate calcite. Photomicrograph by Charuwan Khowpong; field of view $0.80 \mathrm{~mm}$.

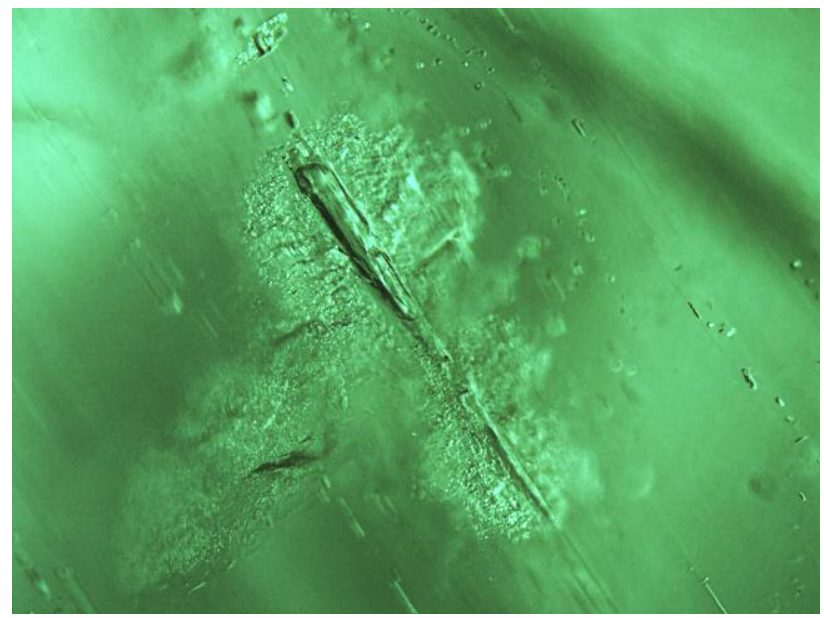

Figure 32. Elongate three-phase inclusion with concentric equatorial fractures in a Brazilian emerald. Photomicrograph by Patcharee Wongrawang; field of view $1.30 \mathrm{~mm}$.

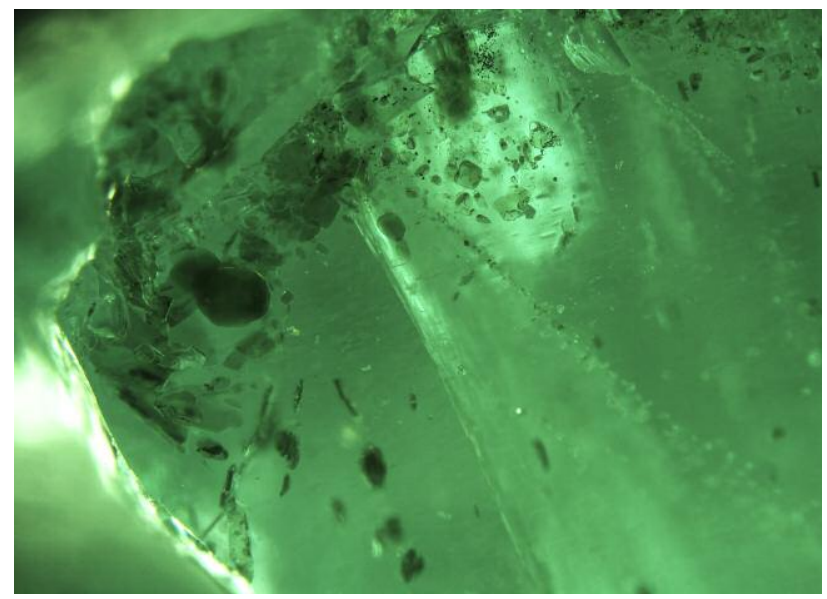

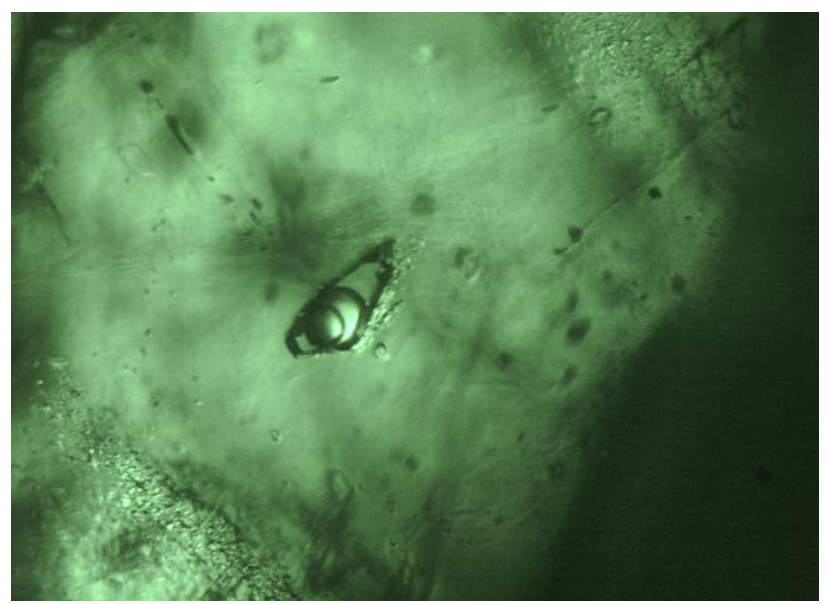

Figure 31. Irregular three-phase inclusion (liquid/liquid/gas) with immiscible liquids and a gas bubble in a Brazilian emerald. Photomicrograph by Charuwan Khowpong; field of view $1.00 \mathrm{~mm}$.

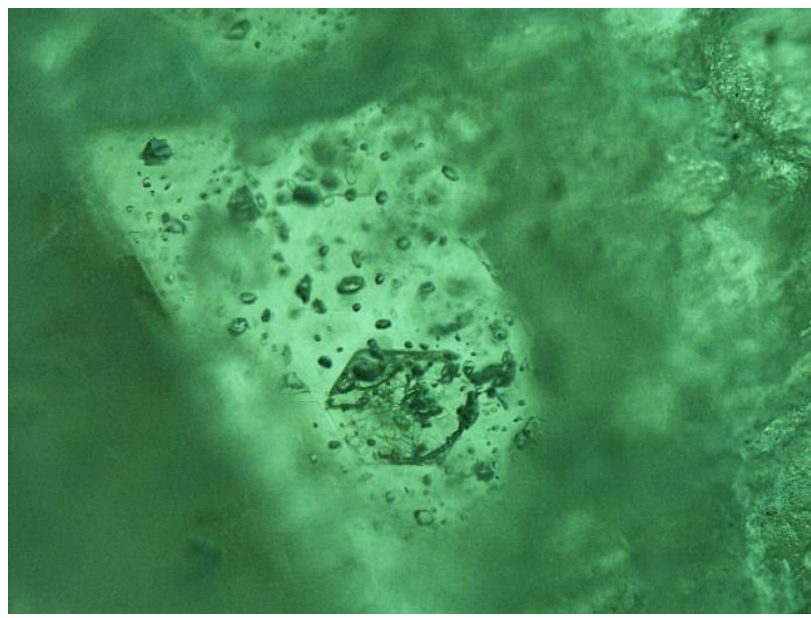

Figure 33. Brownish mica flakes (syngenetic) showing a nearly ideally formed pseudo-hexagonal shape in a Brazilian emerald. Photomicrograph by Charuwan Khowpong; field of view $0.70 \mathrm{~mm}$.

fluid inclusions in Brazilian emeralds may have concentric equatorial fractures (figure 32). Mica can be found as both syngenetic pseudo-hexagonal (figure 33) and protogenetic rounded brown crystals (figure 34). Other solid mineral inclusions such as quartz, magnetite, chromite spinel, calcite, or pyrite can also be observed, similar to other deposits of schist-hosted emerald.

Figure 34. Crystals of rounded dark brownish biotite-phlogopite mica flakes in a Brazilian emerald. Photomicrograph by $P$. Wongrawang; field of view $2.70 \mathrm{~mm}$ 


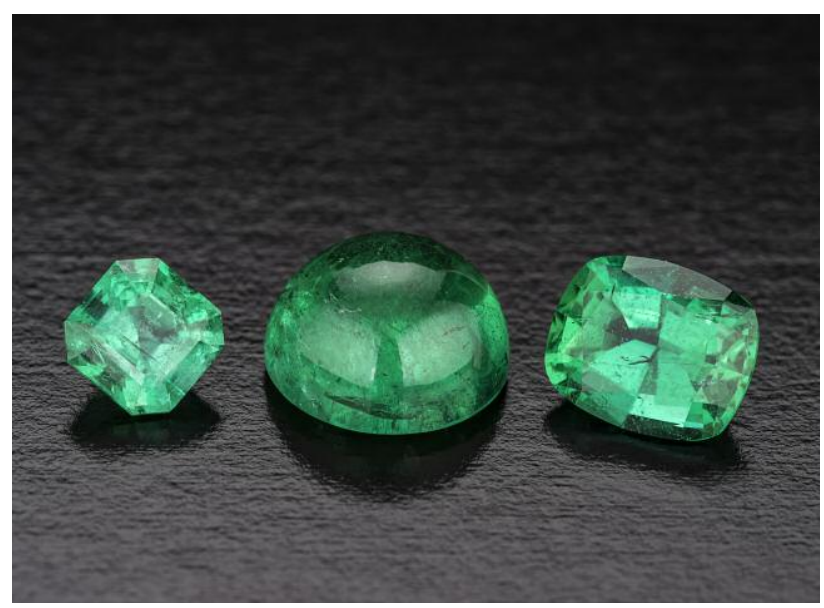

Figure 35. Left to right: Ethiopian emeralds weighing 2.00, 9.72, and $4.13 \mathrm{ct}$. Photo by Robert Weldon/GIA; courtesy of Mayer «) Watt.

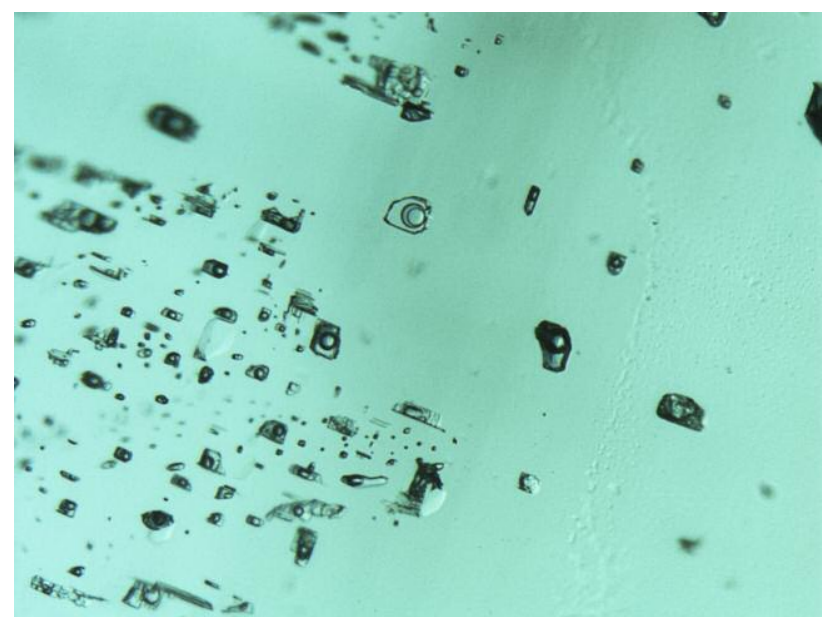

Figure 37. Blocky and irregular fluid inclusions in an Ethiopian emerald. Photomicrograph by Jonathan Muyal; field of view $1.44 \mathrm{~mm}$.

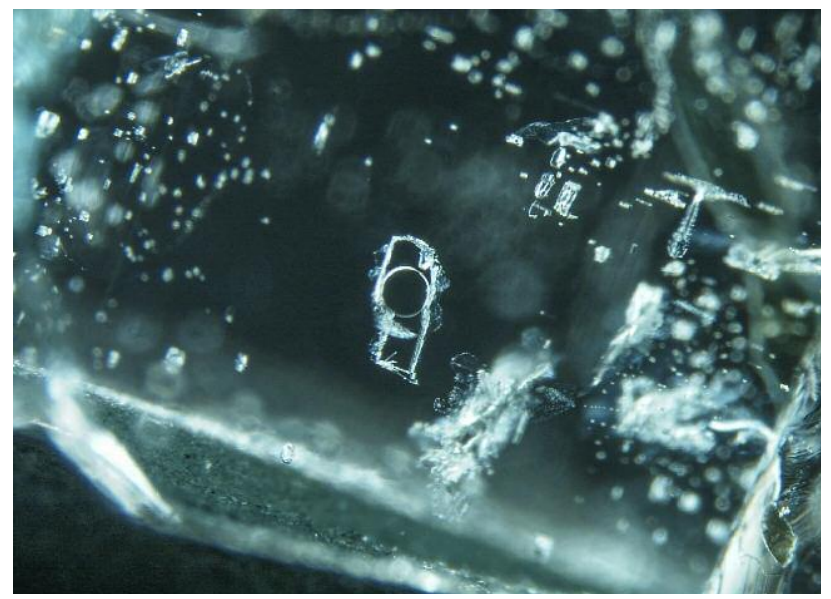

The Internal World of Ethiopian Emeralds. In late 2016, emerald was discovered in Ethiopia near the village of Shakiso (figures 35 and 36). Their fluid inclusions often reveal blocky, elongate, or irregular multiphase inclusions (figures 37-39) and nail-like growth blockage inclusions (figure 40). The blocky inclusions are very similar to those seen in emeralds from Zambia (Kafubu), Brazil, and Russia. Some fluid inclusions in Ethiopian stones contain two separate liquid phases, one gas bubble, and often solid crystals

Figure 39. Irregular fluid inclusion with large gas bubble in an Ethiopian emerald. Photomicrograph by Ungkhana Atikarnsakul; field of view $2.0 \mathrm{~mm}$. 


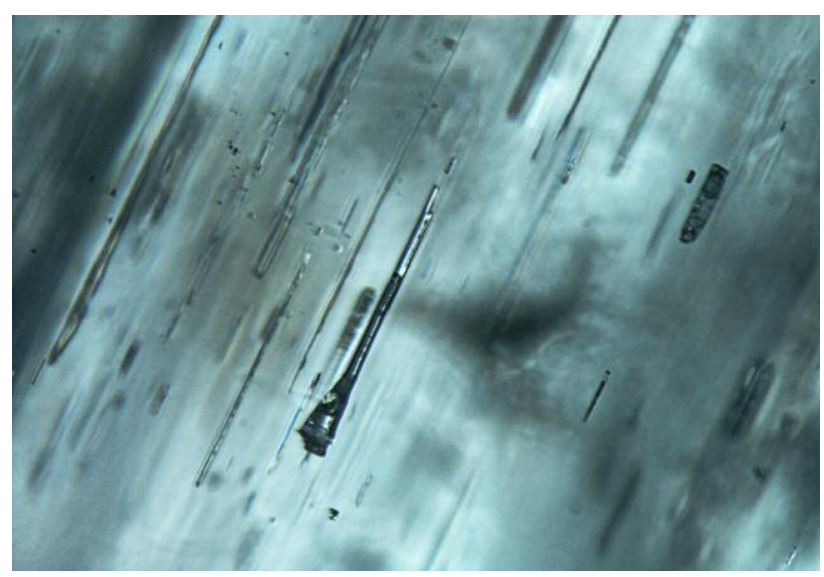

Figure 40. Elongate fluid inclusion originating around a mineral inclusion, resembling "nail head spicules" in an Ethiopian emerald. Photomicrograph by Ungkhana Atikarnsakul; field of view $0.8 \mathrm{~mm}$.

(liquid/liquid/gas) (figures 37-39). When these stones are examined in a microscope using an intense incandescent light, one of the fluids can evaporate and merge with the gas, which has been identified by Raman spectroscopy as a $\mathrm{CO}_{2}$ gas. Some inclusions may also have granular fringes (figure 39). Minute particles and iridescent thin films (figure 41) are seen occasionally and can be confused with inclusion scenes more typical of Russian emerald. Internal growth features are typically straight with angular color zoning following crystal prism faces. Some stones exhibit roiled growth (figure 42) that is distinct from the gota de aceite growth seen in Colombian emeralds. Other mineral inclusions such as brown mica platelets, clinochlore, magnetite spinel, calcite, quartz, and talc can be observed in Ethiopian emerald.

Figure 42. Roiled internal growth in an Ethiopian emerald. Photomicrograph by Ungkhana Atikarnsakul; field of view $2.7 \mathrm{~mm}$.

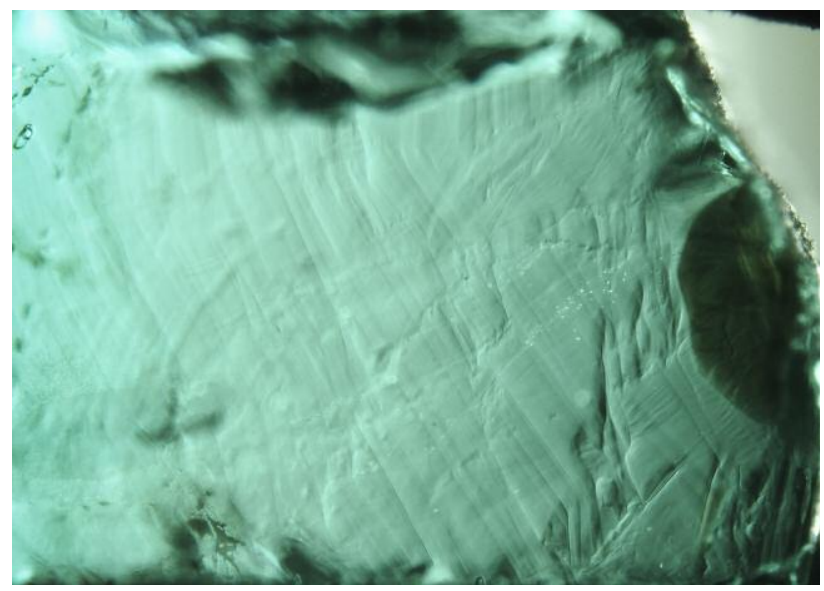

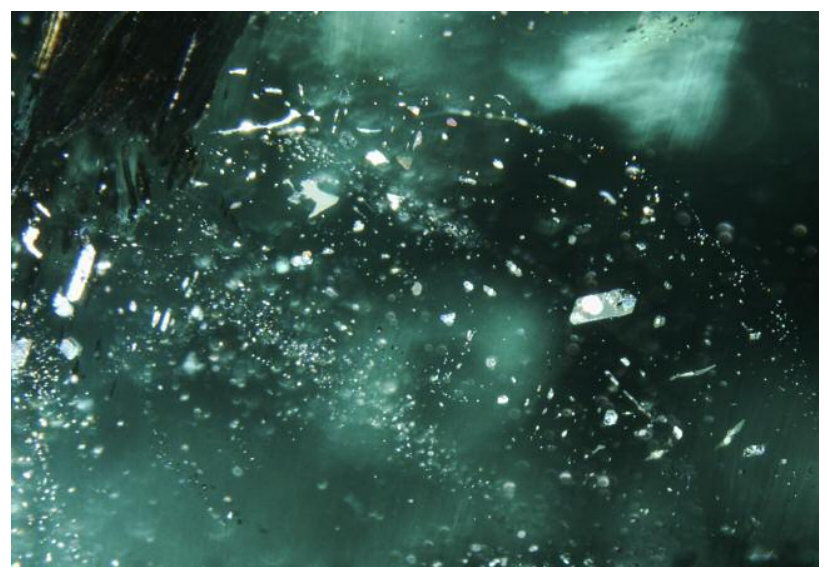

Figure 41. Scattered thin films in an Ethiopian emerald. Photomicrograph by Ungkhana Atikarnsakul; field of view $2.0 \mathrm{~mm}$.

The Internal World of Russian Emeralds. Fine emeralds have been produced from the Ural Mountains since the mid-nineteenth century, placing Russia as one of the classic sources. Russian emeralds can harbor unique inclusion scenes. Iridescent thin films that lie parallel to the basal pinacoid are especially indicative of origin (figure 43). Fluid inclusions take on different forms including elongate (figure 44), irregularly edged multiphase (figures 45 and 46), to blocky (figure 47), although blocky fluid inclusions are uncommon in Russian emeralds. Some fluid inclusions also have patchy, granular fringes (figure 48). Long needles or growth tube inclusions can also be found (figure 49). Brown mica (figure 50) and rod-shaped or needle-like amphibole crystals have been observed. Russian emerald typi-

Figure 43. Plane of numerous interference thin films aligned parallel to the basal pinacoid in a Russian emerald. Photomicrograph by Charuwan Khowpong; field of view $1.40 \mathrm{~mm}$.

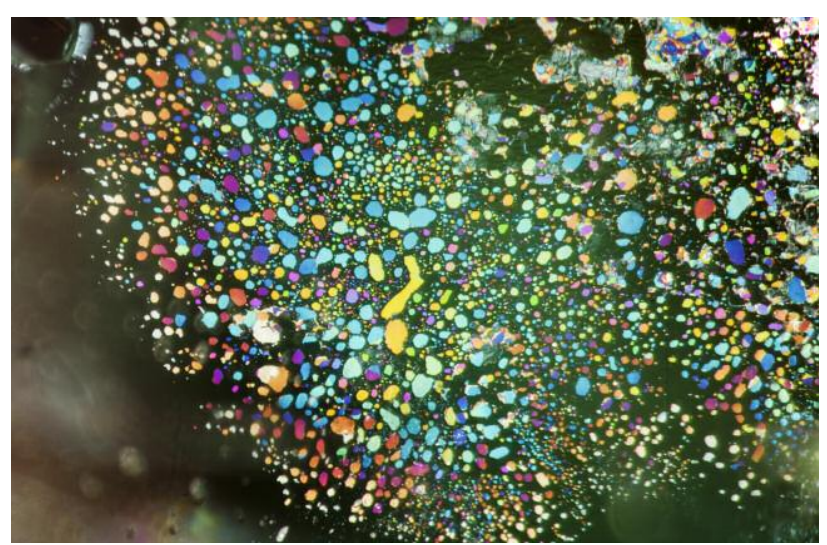




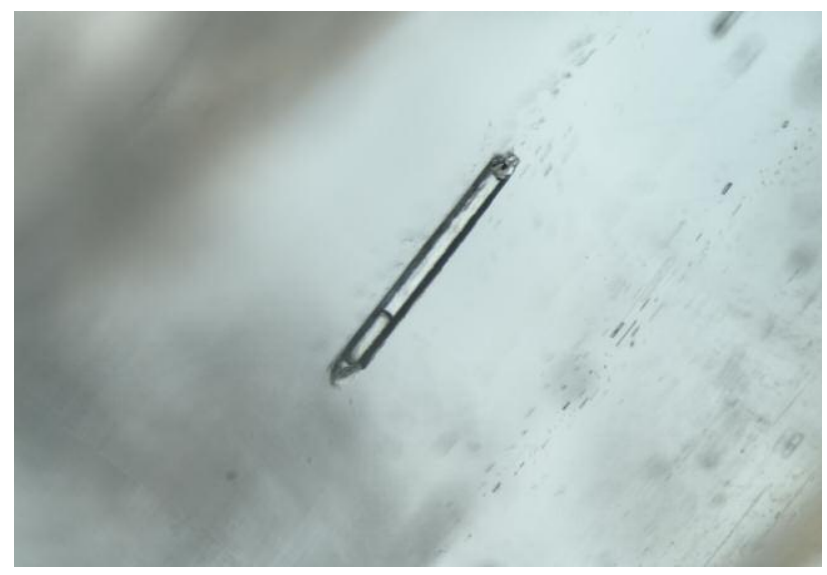

Figure 44. Elongate fluid inclusion with a small solid inclusion at the end in a Russian emerald. Photomicrograph by Suwasan Wongchacree; field of view $1.20 \mathrm{~mm}$.

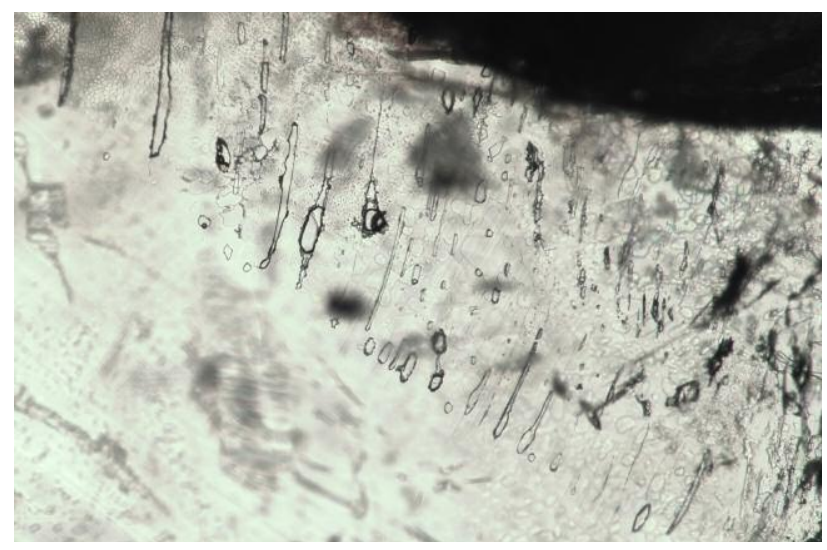

Figure 46. Irregularly shaped fluid inclusions in a Russian emerald. Photomicrograph by Charuwan Khowpong; field of view $1.75 \mathrm{~mm}$.

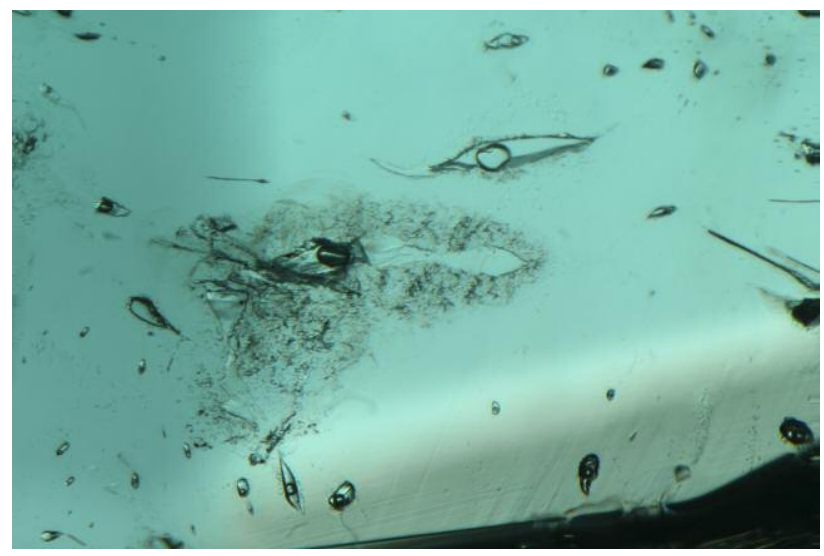

Figure 48. Irregular fluid inclusions with granular fringes in a Russian emerald. Photomicrograph by Aaron Palke; field of view $1.26 \mathrm{~mm}$.

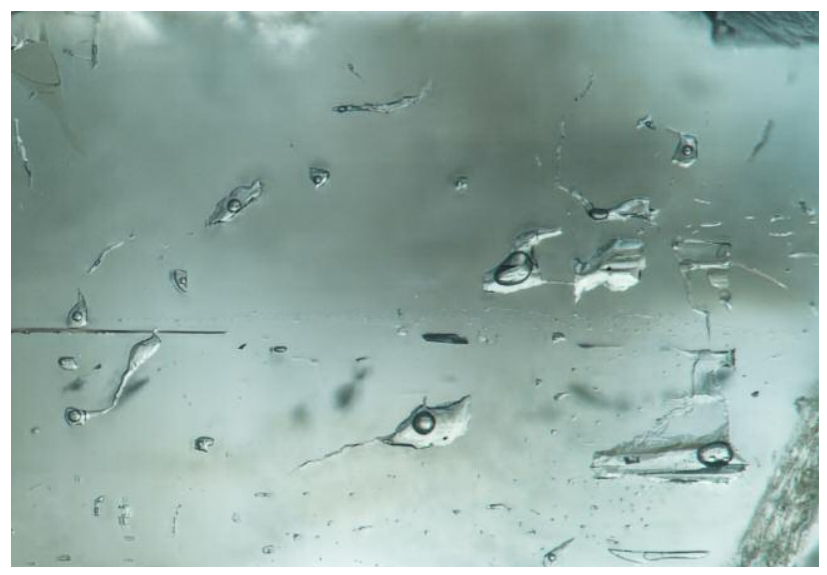

Figure 45. Irregularly shaped two- and three-phase inclusions in a Russian emerald. Photomicrograph by Suwasan Wongchacree; field of view $1.05 \mathrm{~mm}$.

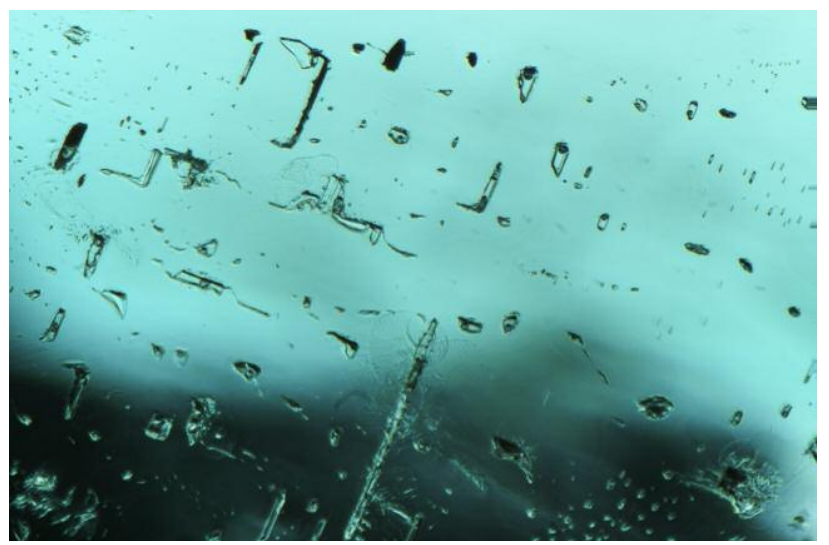

Figure 47. Blocky and irregular fluid inclusions in a Russian emerald. Photomicrograph by Aaron Palke; field of view $1.26 \mathrm{~mm}$.

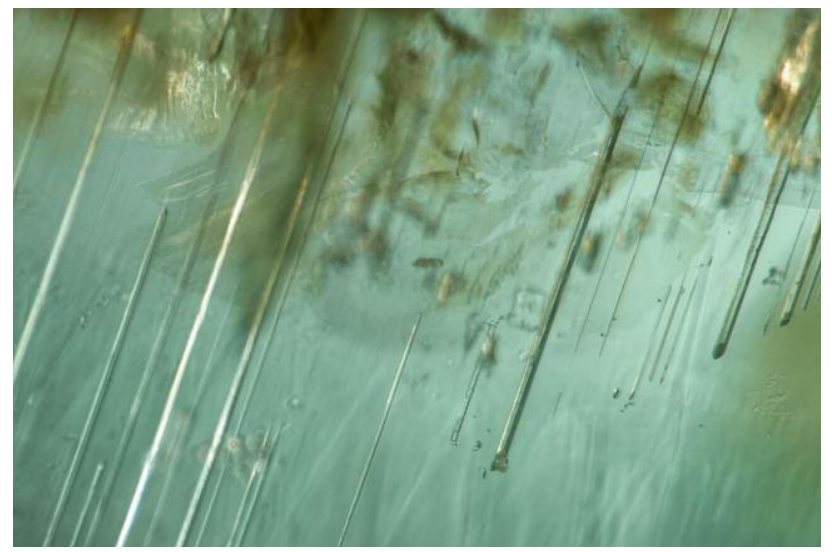

Figure 49. Long growth tubes in a Russian emerald. Fiber-optic illumination. Photomicrograph by Suwasan Wongchacree; field of view $1.05 \mathrm{~mm}$. 


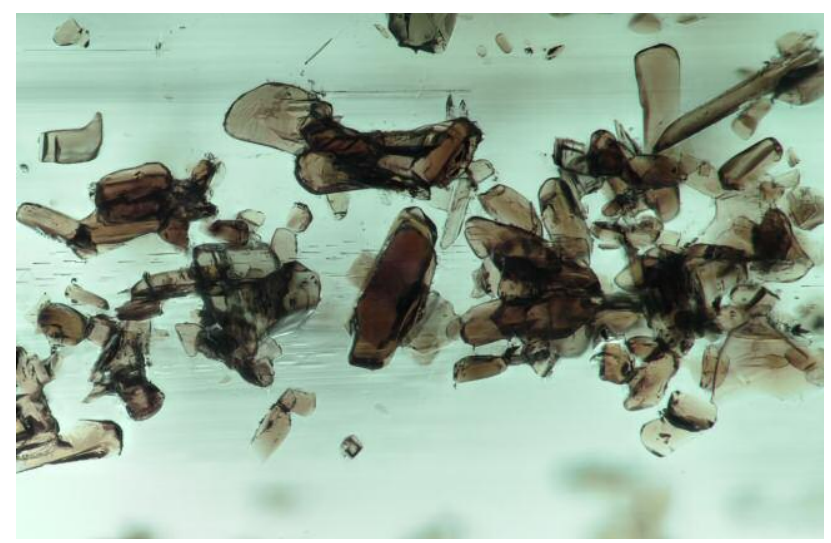

Figure 50. Lath-shaped brown inclusions identified as phlogopite mica in a Russian emerald. Photomicrograph by Suwasan Wongchacree; field of view $1.40 \mathrm{~mm}$.

cally has few inclusions, and origin determination can be challenging.

Inclusion Scenes Gone Wrong. Owing to their similar geological genesis, emeralds from Zambia (Kafubu), Brazil, Russia, and Ethiopia may be difficult to distinguish. Making an accurate origin determination requires an experienced gemologist with a robust reference database to compare against unknown stones. Reaching an origin conclusion is easier when the stone has abundant inclusions as opposed to a clean stone. However, every emerald must be observed carefully, as stones from geographically dis-

Figure 52. Blocky fluid inclusions in Ethiopian emerald might lead to misinterpretation as Zambian origin. Photomicrograph by Ungkhana Atikarnsakul; field of view $1.1 \mathrm{~mm}$.

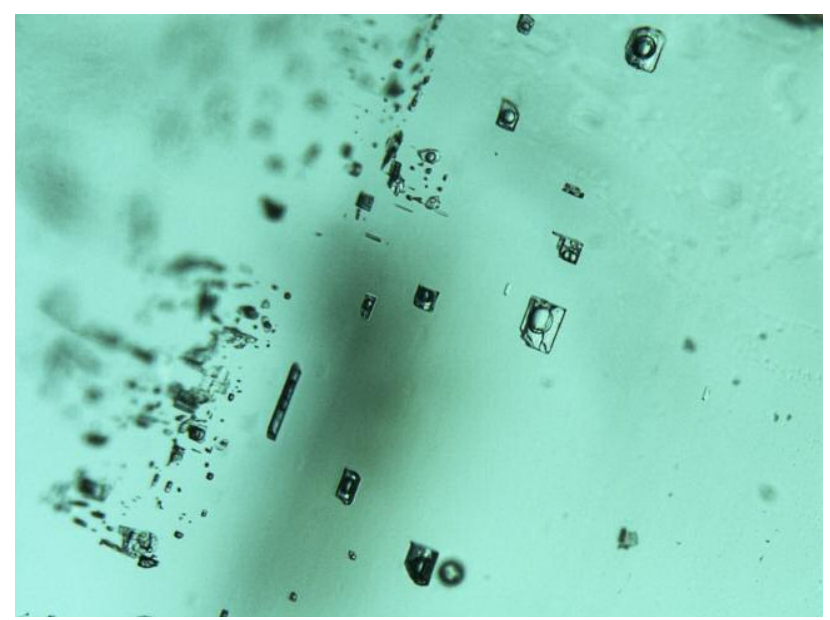

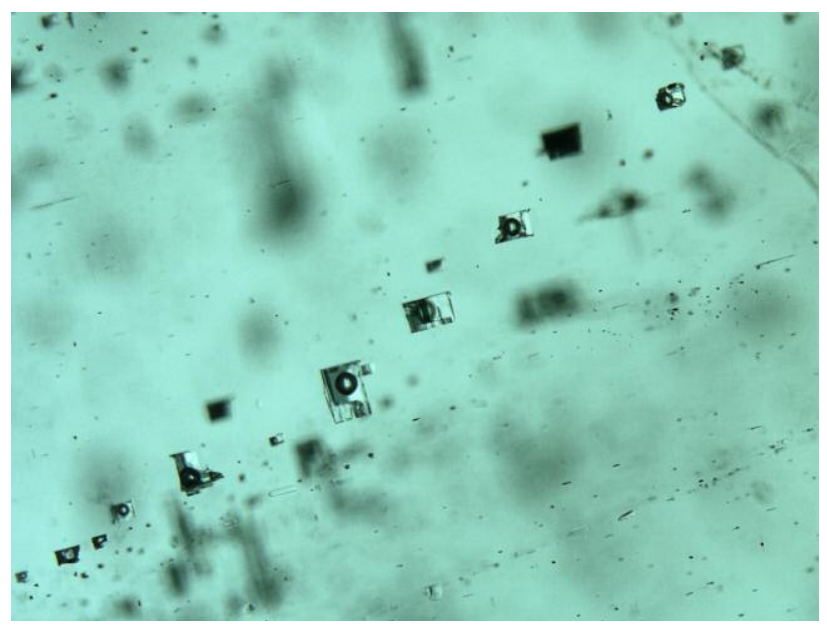

Figure 51. Rectangular blocky fluid inclusions typically seen in Zambian emeralds. Photomicrograph by Nattida Ng-Pooresatien; field of view $1.1 \mathrm{~mm}$.

parate deposits can have similar inclusion scenes. For example, how would you determine origin on these blocky inclusions shown in figures 51 and 52? One is from Zambia and the other from Ethiopia. Irregular fluid inclusions that might have once given an impression of Zambian origin (again, see figure 24) are now also occasionally found in Ethiopian emerald (figure 53). Elongate or thin rod-like fluid inclusions were first seen in Brazilian stones, but similar inclusions have been found in emeralds from Ethiopia and Russia (figure 54). Similarly, rain-like inclusions were once considered diagnostic for Brazilian emerald but can now be observed in Ethiopian and Russian emer-

Figure 53. Irregular fluid inclusions in this Ethiopian emerald were initially interpreted as an indicator of Zambian origin. Photomicrograph by Ungkhana Atikarnsakul; field of view $1.3 \mathrm{~mm}$.

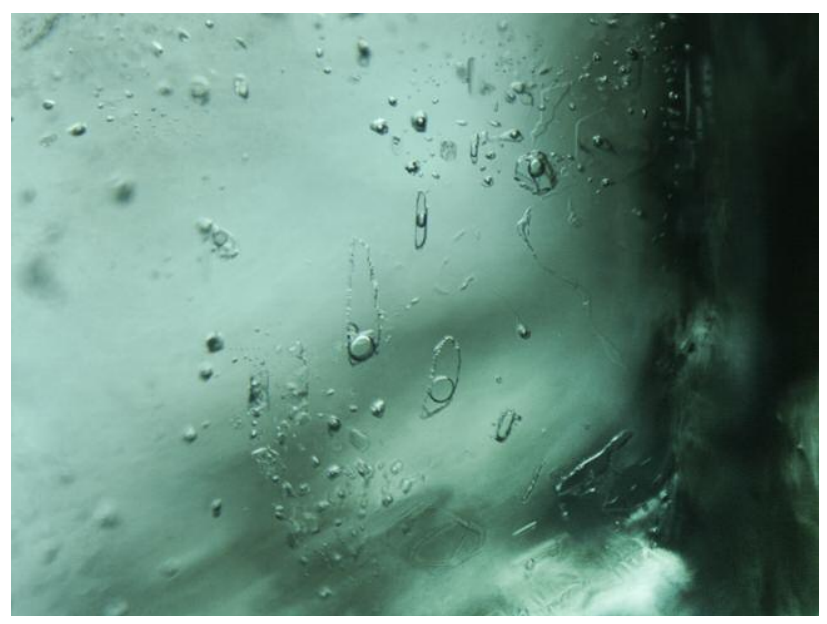




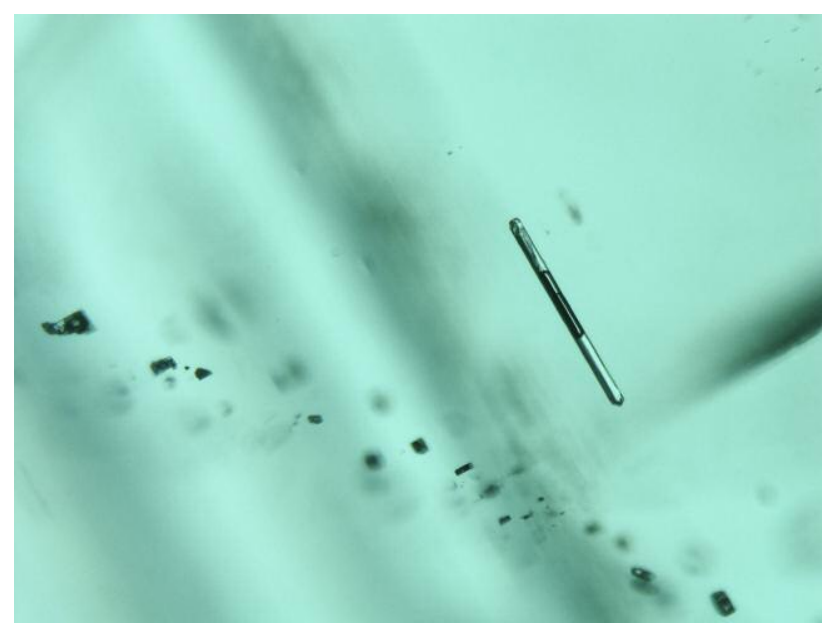

Figure 54. Elongate fluid inclusions in emerald from Ethiopia. These can be also seen in Brazilian and Russian emerald. Photomicrograph by Ungkhana Atikarnsakul; field of view $1.1 \mathrm{~mm}$.

alds as well (figure 55). Clusters of brownish mica are common inclusions in all of these schist-hosted emeralds (figure 56). In this class there are no mineral inclusions that can be used to indicate origin. In many cases it is impossible to give an origin opinion based on microscopy. For emeralds from schist-host rock, UV-Vis-NIR analysis is not useful in separation as they all display similar spectra. In this case, chemical analysis by LA-ICP-MS is required to make an accurate origin determination.

Trace Element Chemistry. Trace element analysis is a much more powerful tool for origin determina-

Figure 56. Cluster of brownish phlogopite mica crystals in Ethiopian emerald. These can also be seen in other schist-hosted emeralds. Photomicrograph by Ungkhana Atikarnsakul; field of view $4.0 \mathrm{~mm}$.

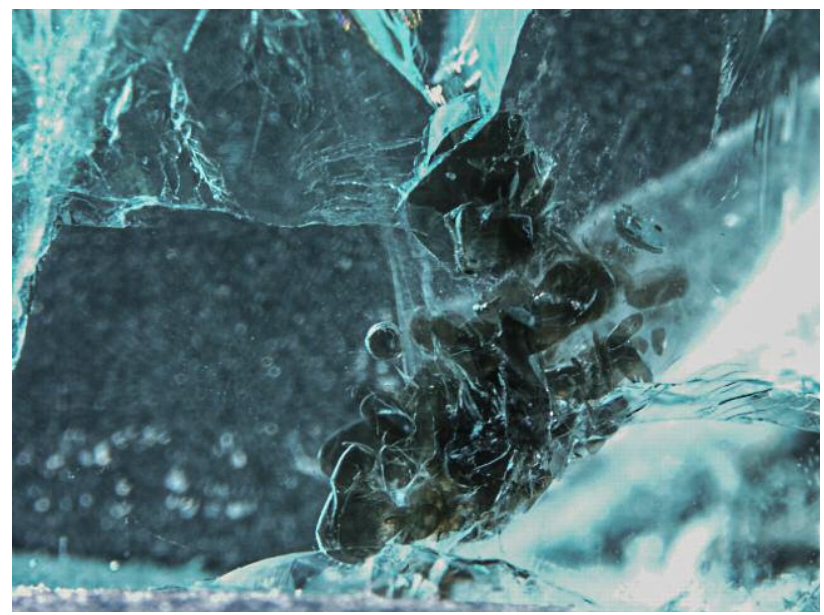

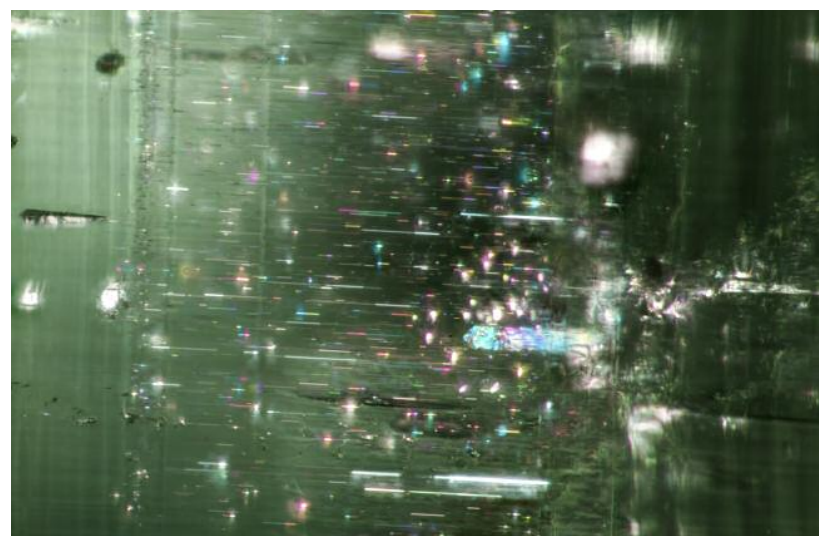

Figure 55. Parallel fine needles in Russian emerald resemble inclusions seen in Brazilian stones. Photomicrograph by Suwasan Wongchacree; field of view $1.05 \mathrm{~mm}$.

tion of emeralds than it is for gem corundum. This likely has its roots in the respective crystalline structures. Beryl has several unique crystal sites of varying sizes and geometry into which trace elements can substitute. This allows easier incorporation and greater variety of substitutional trace elements than for corundum, which has only one crystallographic site that can accept foreign elements. Therefore, emeralds appear to be more sensitive to slight changes in their geological environment, which can impart unique trace element signatures for stones from different geographic localities. Given the overlapping inclusion scenes for emeralds from the deposits discussed here, trace element chemistry analysis is crucial for making accurate origin calls. Several examples of trace element plots used in the GIA laboratory for emerald origin determination are shown in figure 57, and table 1 gives the general ranges and averages of the trace elements used in origin determination at GIA. Commonly used trace elements include $\mathrm{Li}, \mathrm{K}, \mathrm{V}, \mathrm{Cr}, \mathrm{Fe}, \mathrm{Rb}$, and Cs. Colombian emeralds tend to be the purest chemically, possessing generally lower concentrations of the alkalis $\mathrm{Li}, \mathrm{K}, \mathrm{Rb}$, and $\mathrm{Cs}$ as well as $\mathrm{Fe}$. The other hydrothermal/metamorphic emeralds from Afghanistan and China are more enriched in these trace elements, allowing them to be clearly separated from Colombian stones. The most characteristic feature of the schist-hosted emeralds is their enrichment in Fe relative to the hydrothermal/metamorphic group. However, most schist-hosted emeralds also have much higher concentrations of the alkali metals, and members of this group can be generally differentiated from each other by their dis- 


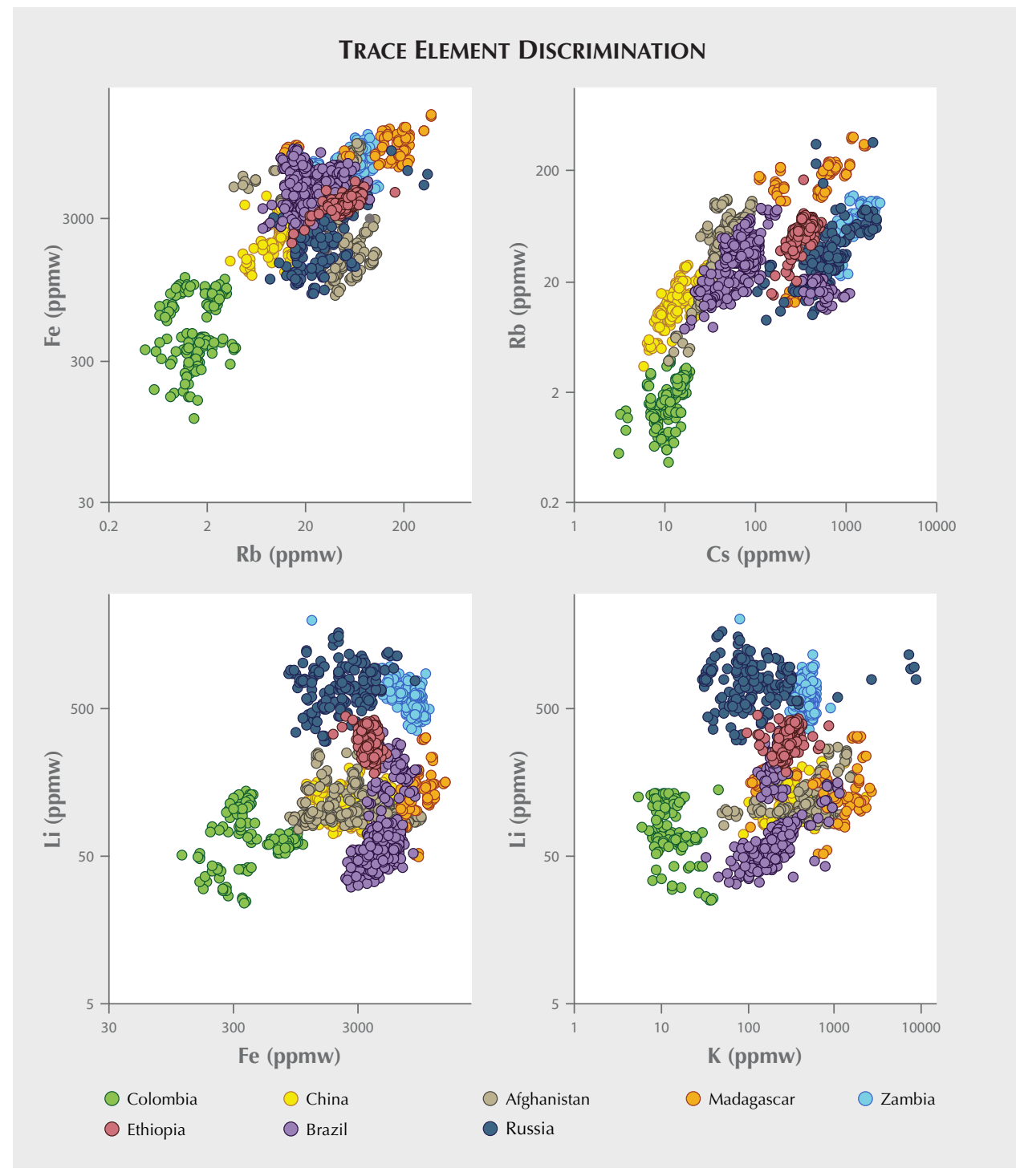

Figure 57. Typical trace element plots used for origin determination of emeralds.

tinctive trace element profiles. For instance, Russian emeralds tend to have lower $\mathrm{Fe}$ and higher $\mathrm{Li}$; Zambian emeralds from Kafubu tend to have high $\mathrm{Cs}, \mathrm{Fe}$, and $\mathrm{Li}$; Madagascar emeralds tend to have high $\mathrm{K}$ and $\mathrm{Fe}$; Ethiopian emeralds tend to be moderately enriched in most trace elements; and Brazilian stones tend to occupy the lower range of many of the trace elements.

Despite these general trace element profiles, there is still significant overlap when considering only one or two trace elements at a time. However, the selective plotting method employed by GIA for blue sapphires and rubies is also routinely used to provide greater confidence in emerald origin determination based on trace element chemistry; see Palke et al. (2019b), pp. 536-579 of this issue, for a discussion of this method. Essentially, selective plotting makes for an easier comparison between an unknown stone and the vast accumulation of reference data available by filtering out data with dissimilar trace element profiles and comparing only against reference stones that match the full trace element signature of the unknown stone. Elements used in the selective plotting method include $\mathrm{Li}, \mathrm{K}, \mathrm{Fe}, \mathrm{Rb}$, and Cs. The use of selective plotting often allows trace element data to be interpreted more easily and provides greater confidence in origin determination based on these data (figure 58). In most cases trace element chemistry provides solid evidence about a stone's origin, but sometimes there is still too much overlap in the trace element data (figure 59). When trace element data and inclusion information are ambiguous or contradictory, an "inconclusive" origin determination is always warranted. 
TABLE 1. Generalized trace element profiles of major world emerald deposits in ppmw.

\begin{tabular}{|c|c|c|c|c|c|}
\hline & \multicolumn{5}{|c|}{ Hydrothermal/Metamorphic Emeralds } \\
\hline & \multicolumn{5}{|c|}{ Colombia } \\
\hline & $\mathrm{Li}$ & K & $\mathrm{Fe}$ & $\mathrm{Rb}$ & Cs \\
\hline Range & $24.2-139$ & bdl-359 & $117-2030$ & bdl-4.92 & $3.17-19.0$ \\
\hline Average & 62.9 & 17.7 & 553 & 2.03 & 10.9 \\
\hline \multirow[t]{3}{*}{ Median } & 61.0 & 14.3 & 414 & 1.96 & 10.7 \\
\hline & \multicolumn{5}{|c|}{ Afghanistan } \\
\hline & $\mathrm{Li}$ & K & $\mathrm{Fe}$ & $\mathrm{Rb}$ & Cs \\
\hline Range & $78.2-268$ & $51.7-1590$ & $849-9820$ & $3.87-110$ & $11.3-97.0$ \\
\hline Average & 115 & 639 & 3780 & 46.9 & 46.2 \\
\hline \multirow[t]{3}{*}{ Median } & 99.7 & 625 & 3120 & 44.1 & 43.6 \\
\hline & \multicolumn{5}{|c|}{ China (Davdar) } \\
\hline & $\mathrm{Li}$ & K & $\mathrm{Fe}$ & $\mathrm{Rb}$ & Cs \\
\hline Range & $68.6-332$ & $91.8-1320$ & $1170-6430$ & $3.47-31.5$ & $5.96-41.2$ \\
\hline Average & 114 & 314 & 2711 & 15.1 & 16.3 \\
\hline \multirow[t]{4}{*}{ Median } & 110 & 303 & 2470 & 14.6 & 13.8 \\
\hline & \multicolumn{5}{|c|}{ Schist-Hosted Emeralds } \\
\hline & \multicolumn{5}{|c|}{ Brazil } \\
\hline & $\mathrm{Li}$ & $\mathrm{K}$ & $\mathrm{Fe}$ & $\mathrm{Rb}$ & Cs \\
\hline Range & $31.3-359$ & $33.2-1150$ & $2460-9120$ & $7.42-91.8$ & $16.8-1130$ \\
\hline Average & 80.8 & 231 & 5120 & 31.4 & 148 \\
\hline \multirow[t]{3}{*}{ Median } & 59.4 & 205 & 5035 & 30.0 & 79.7 \\
\hline & \multicolumn{5}{|c|}{ Ethiopia } \\
\hline & $\mathrm{Li}$ & K & $\mathrm{Fe}$ & $\mathrm{Rb}$ & Cs \\
\hline Range & $183-446$ & 98.6-889 & $1970-5320$ & $14.7-166$ & $151-544$ \\
\hline Average & 310 & 307 & 3841 & 56.9 & 345 \\
\hline \multirow[t]{3}{*}{ Median } & 306 & 306 & 3870 & 58.0 & 351 \\
\hline & \multicolumn{5}{|c|}{ Madagascar } \\
\hline & $\mathrm{Li}$ & $\mathrm{K}$ & $\mathrm{Fe}$ & $\mathrm{Rb}$ & Cs \\
\hline Range & $50.3-320$ & $107-2660$ & $6720-15800$ & $12.7-395$ & $110-1670$ \\
\hline Average & 144 & 1200 & 9400 & 157 & 555 \\
\hline \multirow[t]{3}{*}{ Median } & 127 & 1220 & 8990 & 174 & 541 \\
\hline & \multicolumn{5}{|c|}{ Russia } \\
\hline & $\mathrm{Li}$ & $\mathrm{K}$ & $\mathrm{Fe}$ & $\mathrm{Rb}$ & Cs \\
\hline Range & $300-1640$ & bdl-8830 & $864-8800$ & $9.10-361$ & $107-2180$ \\
\hline Average & 751 & 319 & 2613 & 39.9 & 714 \\
\hline \multirow[t]{3}{*}{ Median } & 723 & 108 & 2330 & 28.5 & 521 \\
\hline & \multicolumn{5}{|c|}{ Zambia (Kafubu) } \\
\hline & $\mathrm{Li}$ & K & $\mathrm{Fe}$ & $\mathrm{Rb}$ & Cs \\
\hline Range & $360-1140$ & $305-890$ & $4620-11600$ & $17.4-116$ & $375-2430$ \\
\hline Average & 604 & 500 & 8139 & 65.9 & 1344 \\
\hline \multirow[t]{3}{*}{ Median } & 600 & 513 & 8410 & 72.6 & 1480 \\
\hline & \multicolumn{5}{|c|}{ Detection Limits (ppmw) } \\
\hline & $\mathrm{Li}$ & $\mathrm{K}$ & $\mathrm{Fe}$ & $\mathrm{Rb}$ & Cs \\
\hline Range & $0.016-0.71$ & $0.27-3.15$ & $0.71-5.57$ & $0.003-0.040$ & $0.005-0.99$ \\
\hline
\end{tabular}




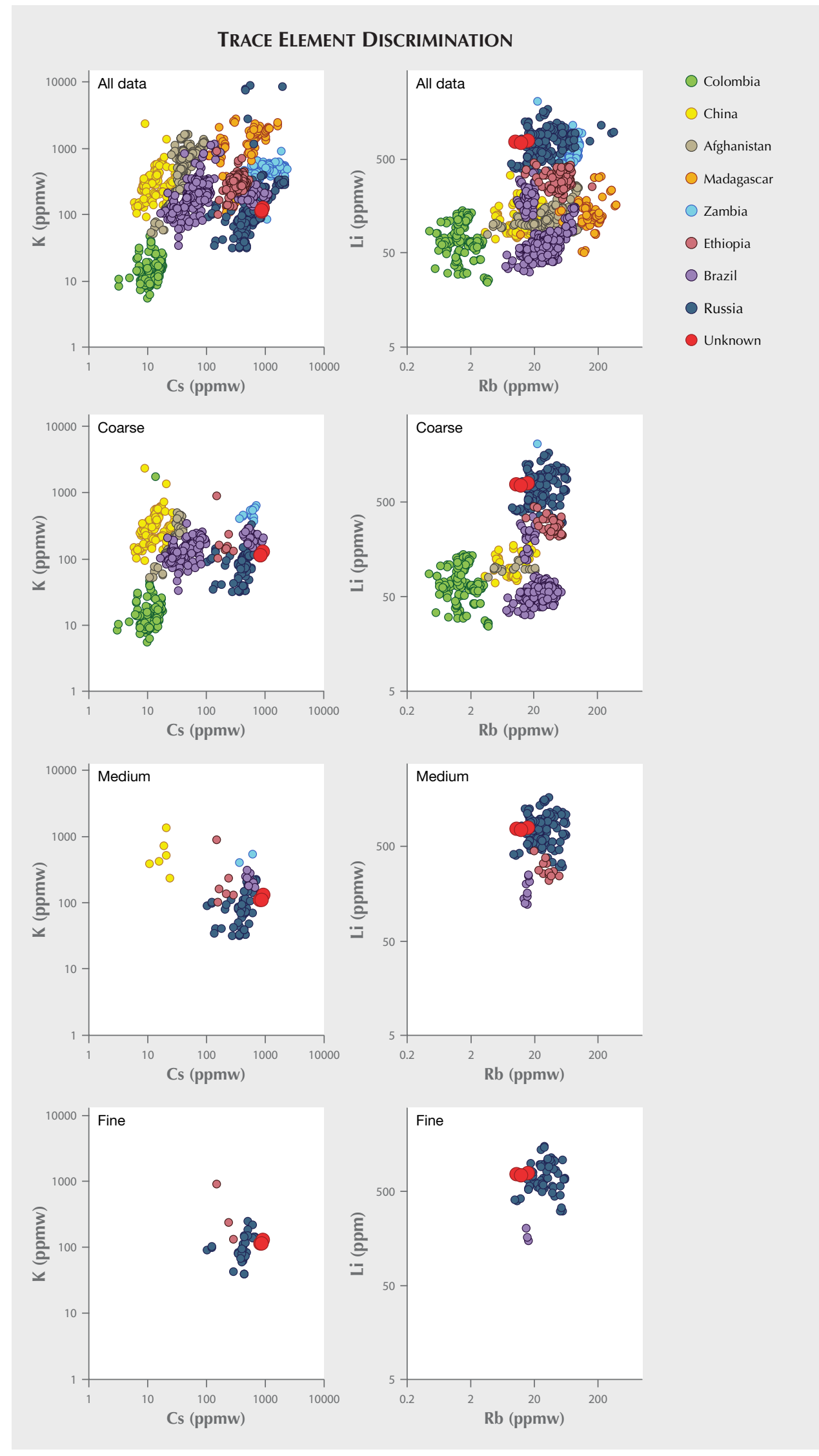

Figure 58. Example of a Russian emerald's origin determined using the selective plotting method (the unknown stone shown as a red circle). The trace element profile of an unknown emerald can be easier to interpret through the selective plotting method used by GIA. Selective plotting uses coarse, medium, and fine windows to filter out dissimilar reference data, making the plots easier to interpret. 


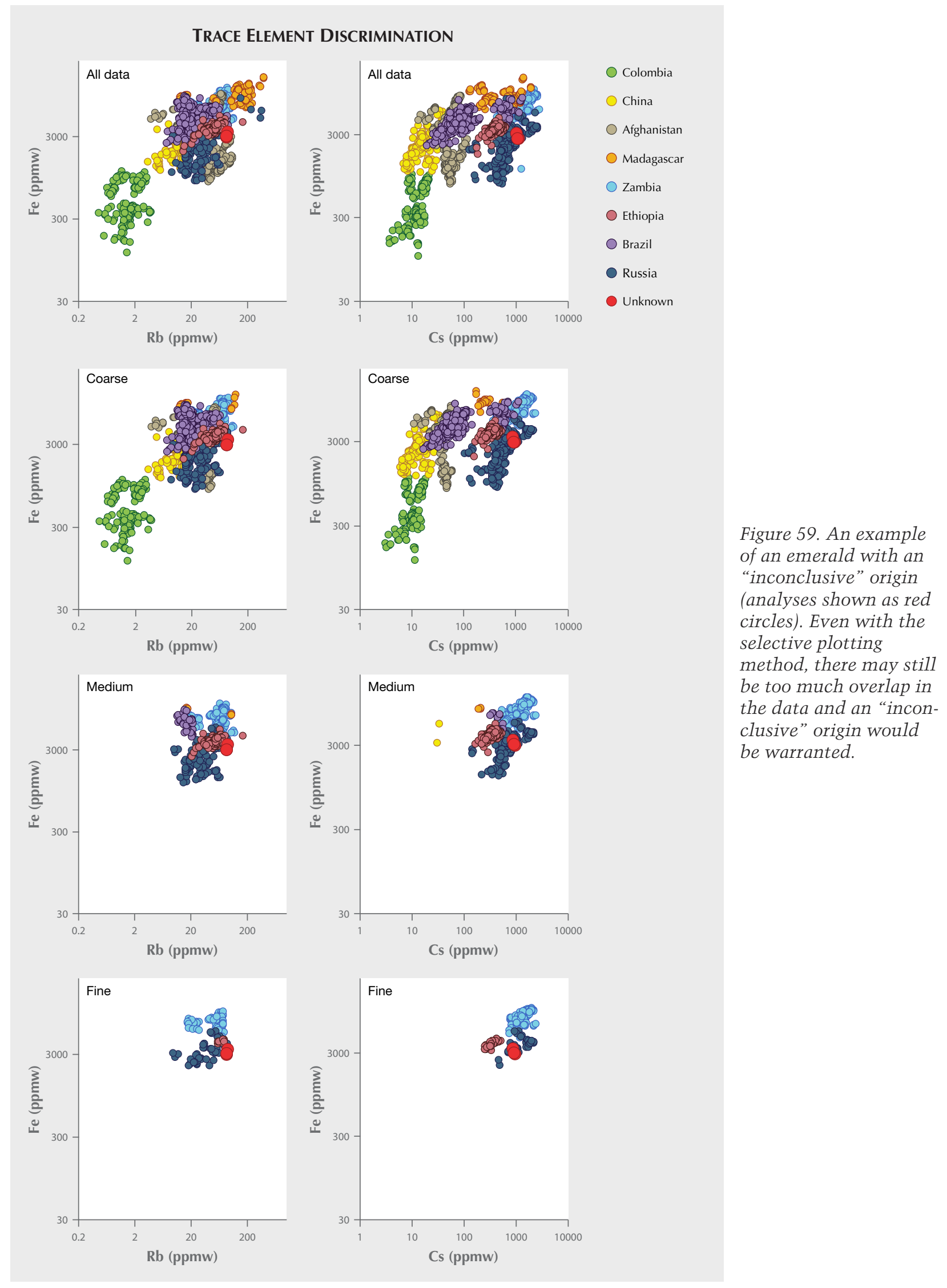




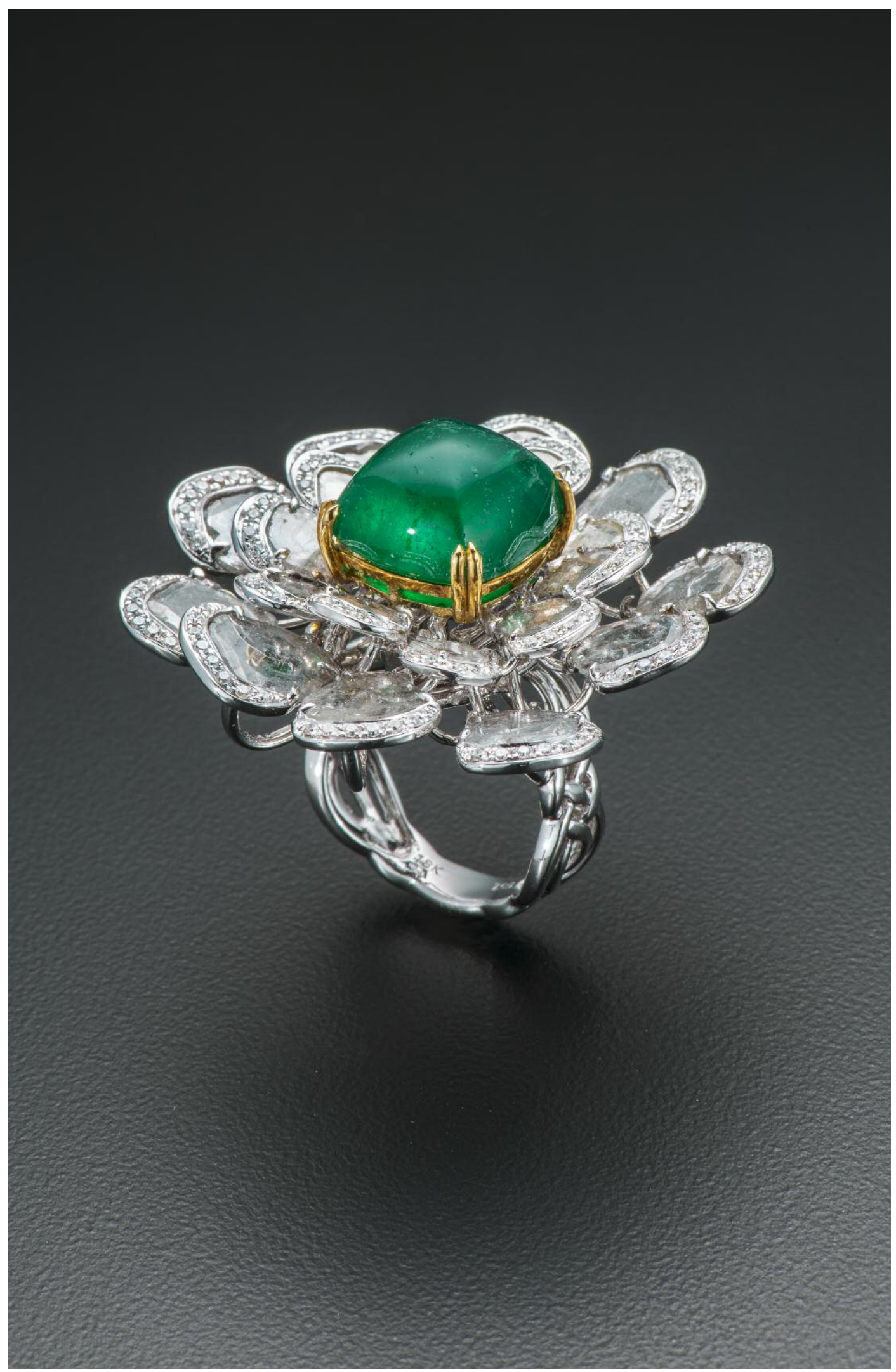

Figure 60. This ring contains a $12.09 \mathrm{ct}$ sugarloaf cabochon emerald. Photo by Robert Weldon/GIA; courtesy of Pioneer Gems. 


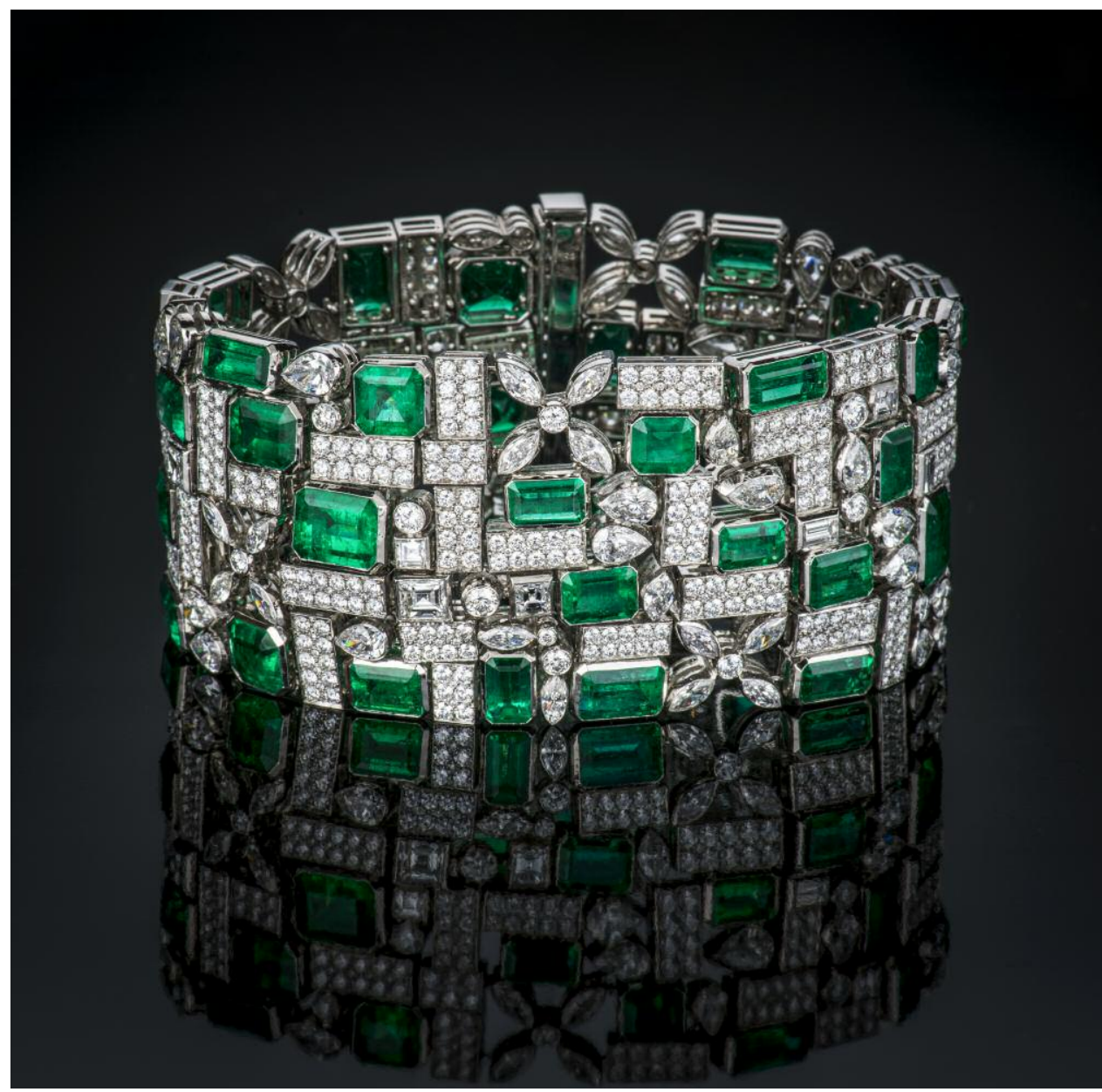

Figure 61. The emeralds in this bracelet, 48.91 carats total, are from the Chivor mine in Colombia. Photo by Robert Weldon/GIA; courtesy of Pioneer Gems.

\section{CONCLUSIONS}

With the proliferation of sources across the world in the twenty-first century, emerald origin determination has become an increasingly important service offered by gemological laboratories. At GIA, origin determinations are supported by years of meticulous efforts by the field gemology department in assembling a robust reference collection and collecting data on these samples (Vertriest et al., 2019 , pp. 490-511 of this issue). This continual accumulation of information has forced the laboratory to adapt its methods and criteria for origin determination to keep up with the evolution of the world emerald market (figures 60 and 61). Given the finding of jagged three-phase fluid inclusions in low-Fe emeralds from Afghanistan and China, any stone that gives an initial impression of a Colombian origin must be carefully scrutinized to avoid inaccurate origin conclusion. The rise of Ethiopian emerald in the last few years has also forced the lab to come to terms with these new stones and their inclusion scenes, which can overlap with Brazilian, Russian, and Zambian emeralds. The lab has also had to understand the increased likelihood of seeing Russian emeralds from the Mariinsky (Malysheva) mine near Ekaterinburg in the Russian Urals. For any non-Colombian emeralds, trace element chemistry is always needed to support an origin determination, given the potential for overlap in their internal features. And yet, despite the years of experience collecting and analyzing data and documenting changes to the emerald mining scene, there are still some stones for which the lab is obligated to issue "inconclusive" origin opinions. Most of the time this is due to a trace element profile that does not match any of the reference data or because of ambiguous or contradictory inclusion scenes. Efforts by the laboratory and the field gemology department will be crucial to closing gaps in our knowledge and keeping on top of further developments in the world of emeralds-whatever the future may hold. 


\section{CASE Study 1: Zambian EMERALD}

In the first emerald case study, we will analyze the 0.57 ct step-cut emerald shown in figure CS 1-1. The first step in determining this stone's geographic origin is to collect a UV-Vis-NIR absorption spectrum. The absorption spectrum (figure CS 1-2) shows a pronounced $850 \mathrm{~nm}$ absorption band in the near-infrared region. This identifies the stone as a schist-hosted emerald, essentially narrowing the options for its geographic origin to Zambia, Brazil, Russia, Ethiopia, and Madagascar. Microscopic observation shows a field of blocky fluid inclusions (figure CS 1-3), typical for schist-hosted emeralds. At this point, trace element chemistry is required to ensure an accurate origin determination. Representative trace element plots using data from LA-ICP-MS measurements are shown in figure CS 1-4. Use of the selective plotting method (see Palke et al., 2019b, pp. 536-579 of this issue) clearly shows that this stone is consistent with a Zambian origin. Taken together, the analytical data collected allows a conclusive origin determination of Zambia.

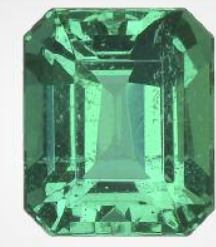

Figure CS 1-1. This 0.57 ct step-cut emerald is at the center of this origin determination case study. Photo by Diego Sanchez.

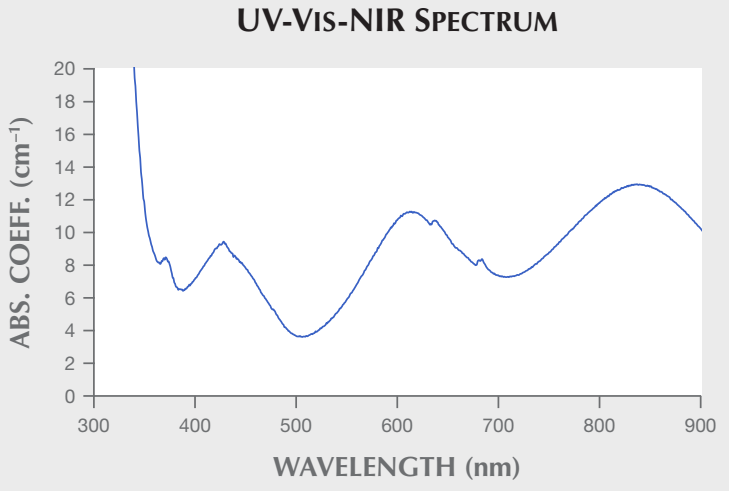

Figure CS 1-2. UV-Vis-NIR absorption spectroscopy indicates a schist-hosted deposit such as Zambia, Ethiopia, or Brazil.

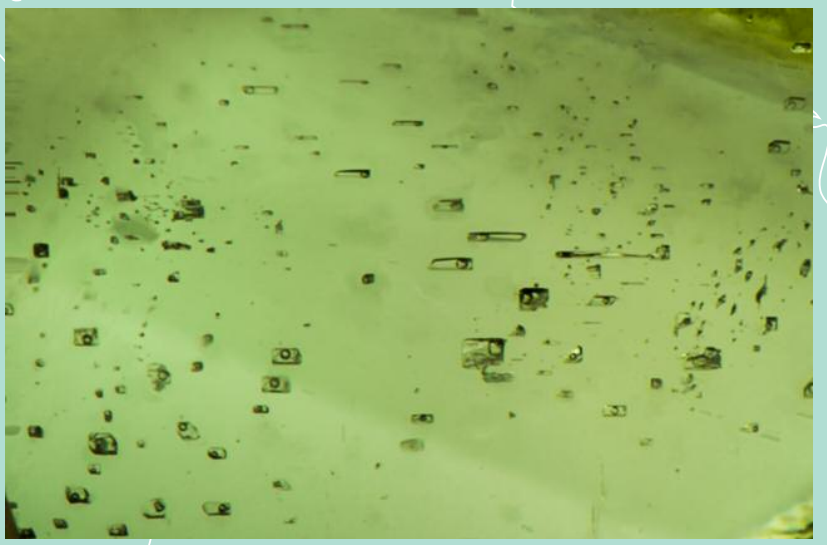

Figure CS 1-3. Blocky fluid inclusions also indicate a schist-hosted deposit such as Zambia, Ethiopia, or Brazil. Photomicrograph by Aaron Palke; field of view $1.72 \mathrm{~mm}$. 


\section{TRACE ELEMENT DisCriminATION}
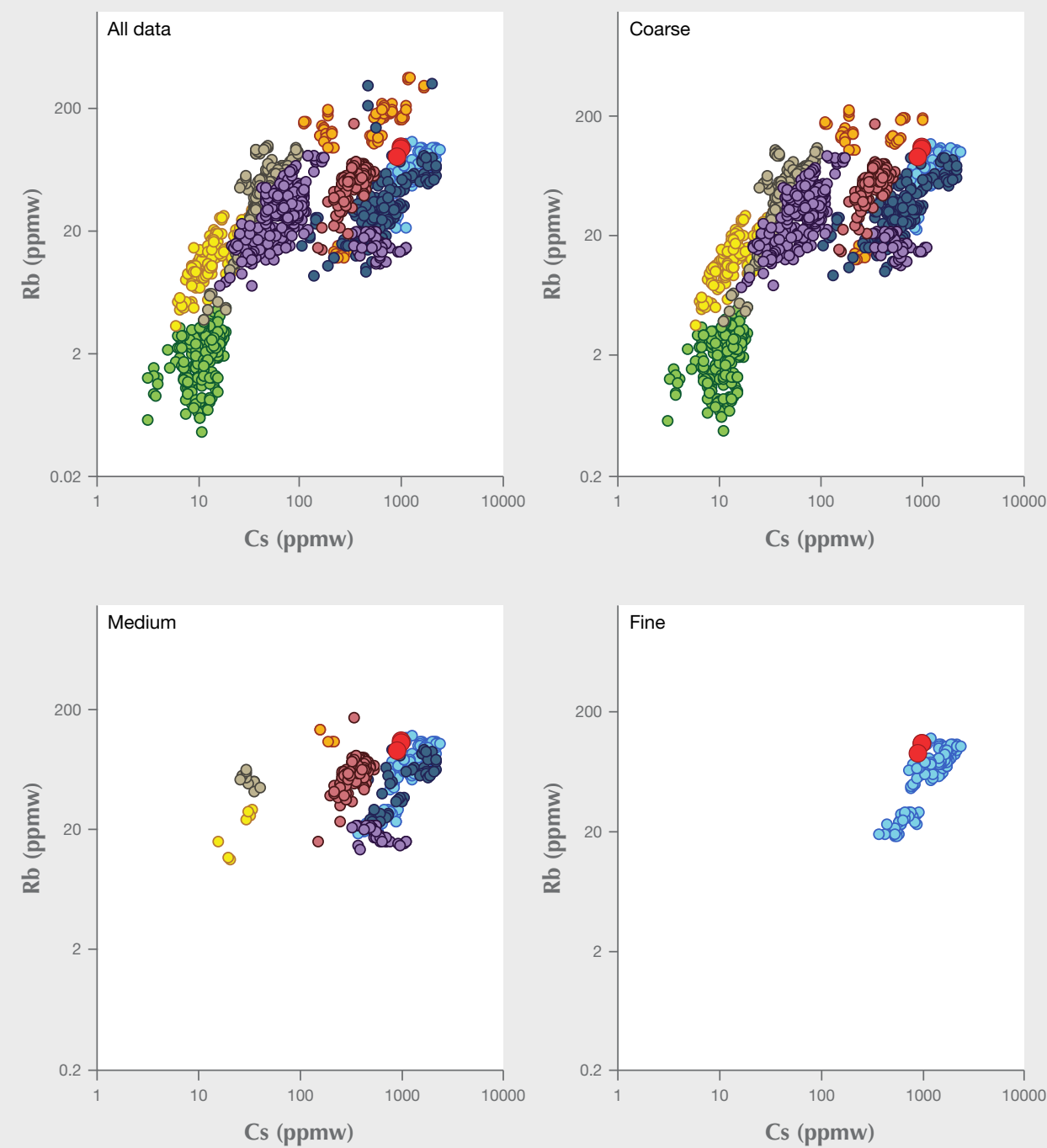
Colombia
China
Afghanistan
Madagascar
Zambia
Ethiopia
Brazil
- Russia
- Unknown

Figure CS 1-4. Trace element analysis supports a Zambian origin. The selective plotting method was used with coarse, medium, and fine filters. 


\section{CASE Study 2: Colombian EMerald}

The 2.04 ct step-cut emerald shown in figure CS $2-1$ is the focus of this case study. The origin determination procedure starts with the stone's UV-Vis-NIR spectrum (figure CS 2-2). There is only a very slight rise in the absorption spectrum beyond $700 \mathrm{~nm}$ and into the near-infrared region. This indicates a very likely Colombian origin, though an Afghan or Chinese origin cannot be completely ruled out, as some emeralds from those locales show similar UV-Vis-NIR spectra. The most noteworthy inclusions are jagged fluid inclusions, which also give a distinct impression of Colombian pedigree (figure CS 2-3). Once again, this information must be considered carefully as some emeralds from China, Afghanistan, and Zambia (Musakashi) can show somewhat similar inclusions. Therefore, trace element analysis is needed. Representative trace element plots (figure CS 2-4) clearly indicate a Colombian origin. Note that the selective plotting method was not employed here and is generally not needed for Colombian emeralds.

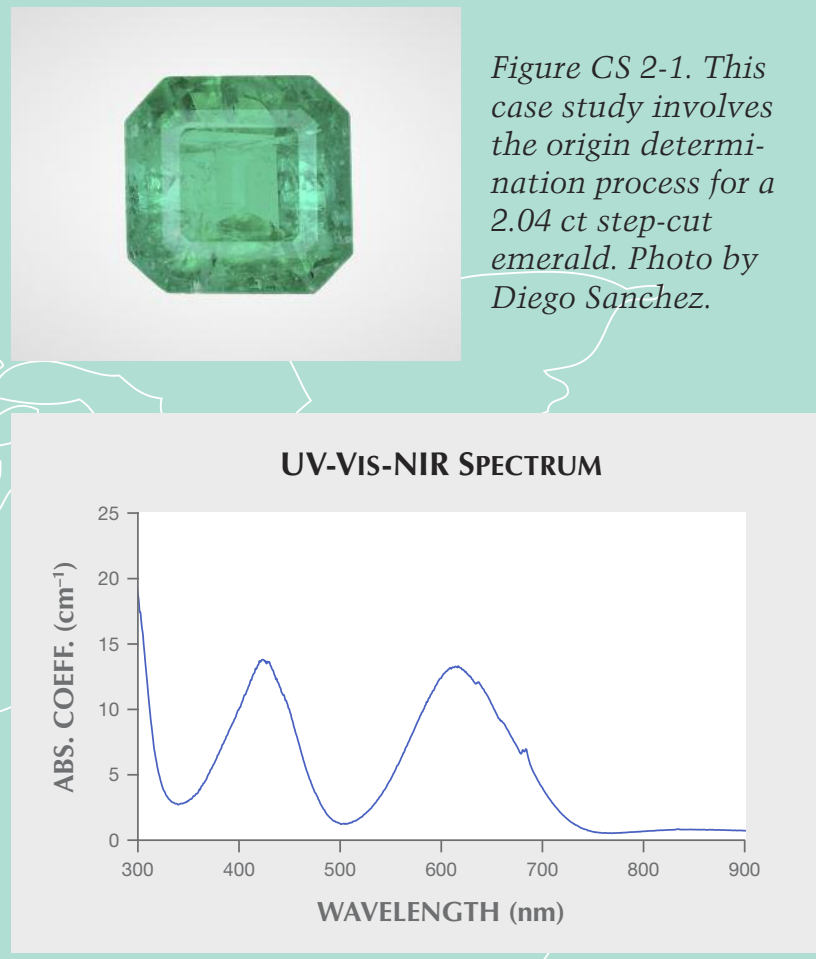

Figure CS 2-2. UV-Vis-NIR absorption spectroscopy suggests an origin in a metamorphic-related deposit such as Colombia, Afghanistan, or China.

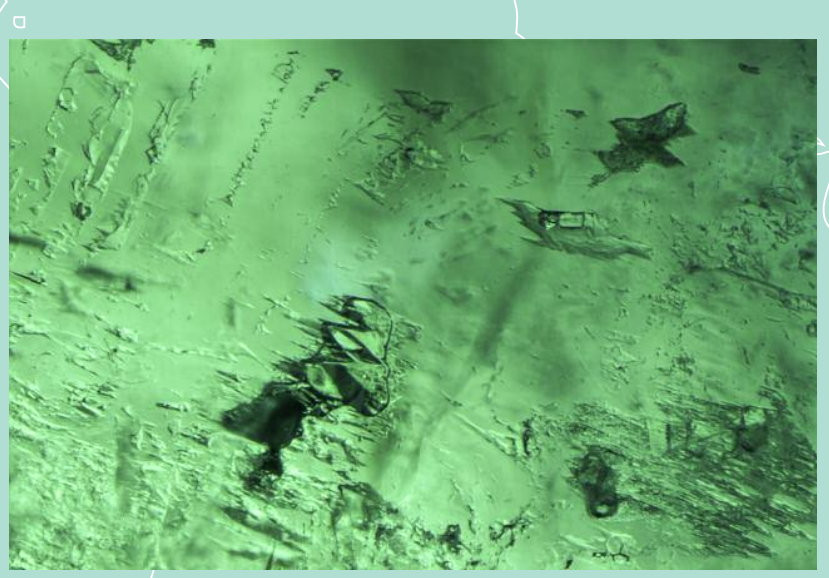

Figure CS 2-3. Jagged fluid inclusions strongly indicate a Colombian origin. Photomicrograph by Nathan Renfro; field of view $1.31 \mathrm{~mm}$. 


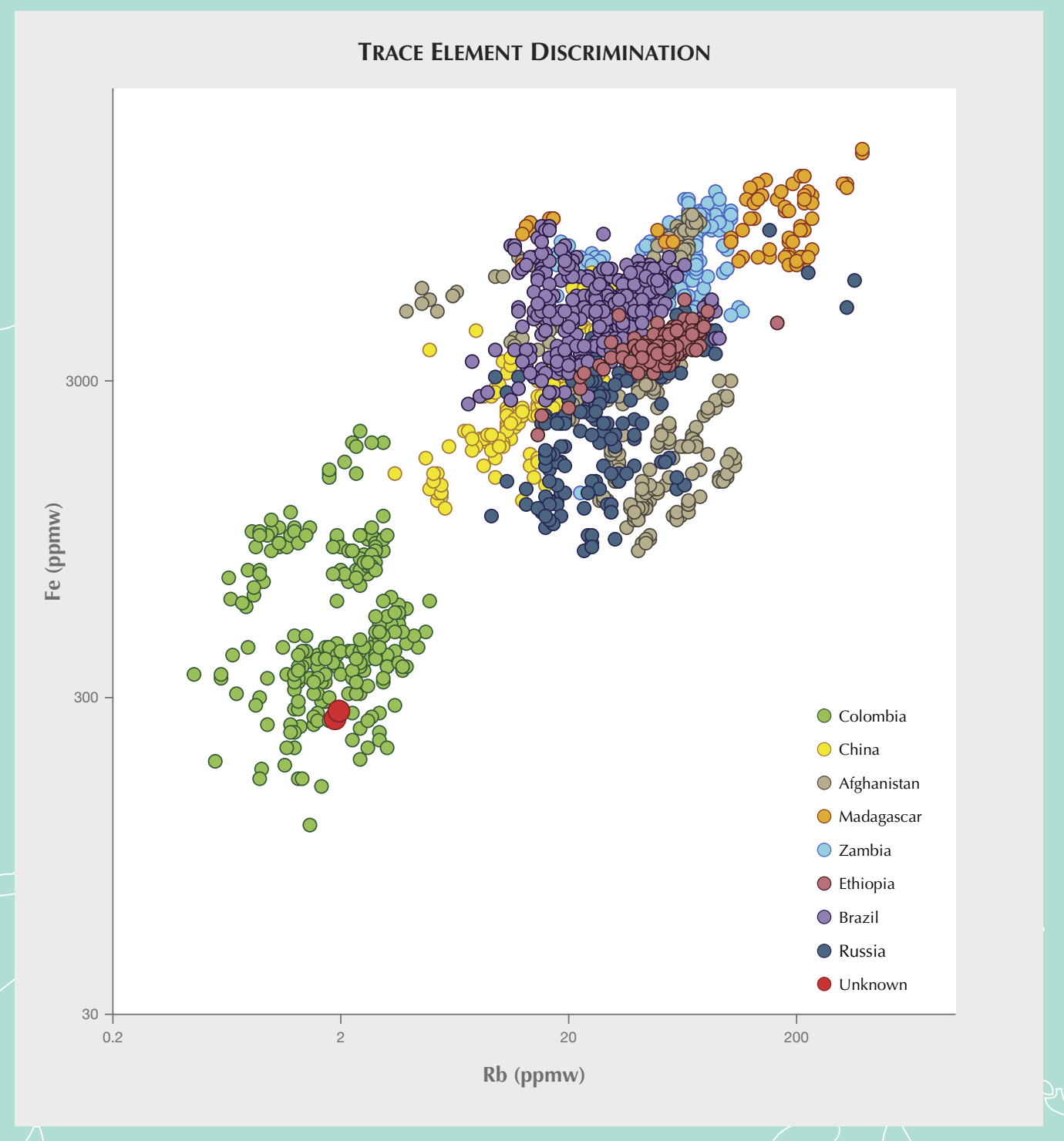

Figure CS 2-4. Trace element analysis corroborates a Colombian origin for this emerald, shown as the red circle. 


\section{CASE Study 3: InCONCLUSive EMERALD}

Figure CS 3-1 shows a 1.05 ct step-cut emerald under consideration for a geographic origin determination. GIA's standard procedure for emerald origin determination is to start by collecting a UV-Vis-NIR absorption spectrum (figure CS 32). The rise in absorption beyond $700 \mathrm{~nm}$ and into the near-infrared clearly indicates that this stone belongs to the schist-hosted emerald group. Therefore, the origins we will consider are Zambia, Brazil, Russia, Ethiopia, and Madagascar. Microscopic observations of the inclusion characteristics reveal irregularly shaped fluid inclusions, which are typical of many schist-hosted emeralds but do not clearly indicate any specific origin (figure CS 3-3). Finalizing the geographic origin determination on this stone requires trace element chemistry measurements. Figure CS 3-4 shows representative trace element plots in comparison with reference stones of known provenance from GIA's colored stone reference collection. Unfortunately, this stone does not seem to uniquely match any specific geographic location. Without the use of selective plotting, the Fe-Li plot seems to suggest a Madagascar origin. However, other plots show that this stone lies outside the field of the Madagascar reference data. Therefore, with the reference collection data we have so far and with the application of selective plotting, Madagascar does not appear to be a viable option. With more reference data, hopefully stones such as this one will be able to match to data. Until then, given the ambiguity in the data, the only possible option today for this emerald is an "inconclusive" origin call.

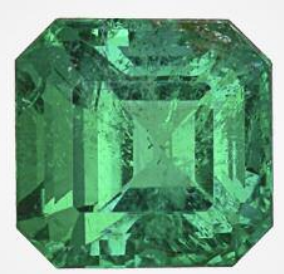

Figure CS 3-1. This 1.05 ct step-cut emerald is the focus of this origin determination case study. Photo by Diego Sanchez.

UV-VIS-NIR SPECTRUM

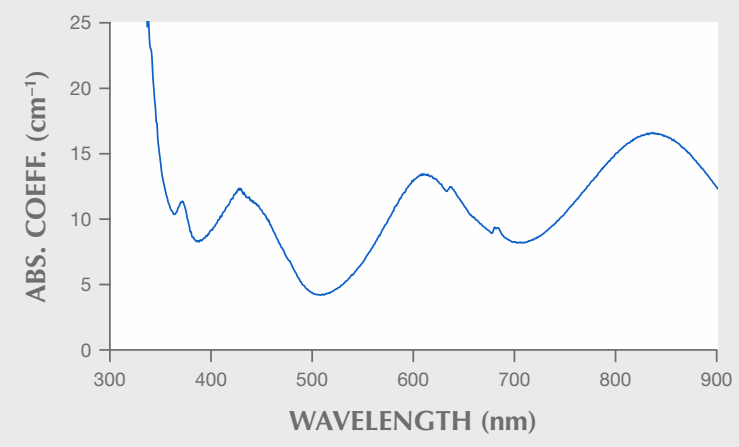

Figure CS 3-2. UV-Vis-NIR absorption spectroscopy indicates a schist-hosted deposit such as Zambia, Russia, Ethiopia, Brazil, or Madagascar.

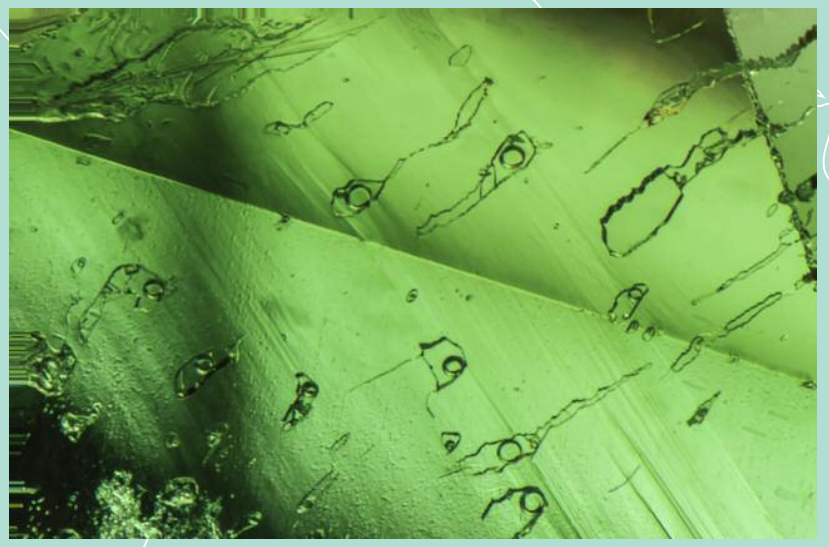

Figure CS 3-3. Irregular fluid inclusions also suggest a schist-hosted emerald deposit such as Zambia, Russia, Ethiopia, Brazil, or Madagascar. Photomicrograph by Aaron Palke; field of view $2.37 \mathrm{~mm}$. 


\section{TRACE ELEMENT DisCriminATION}
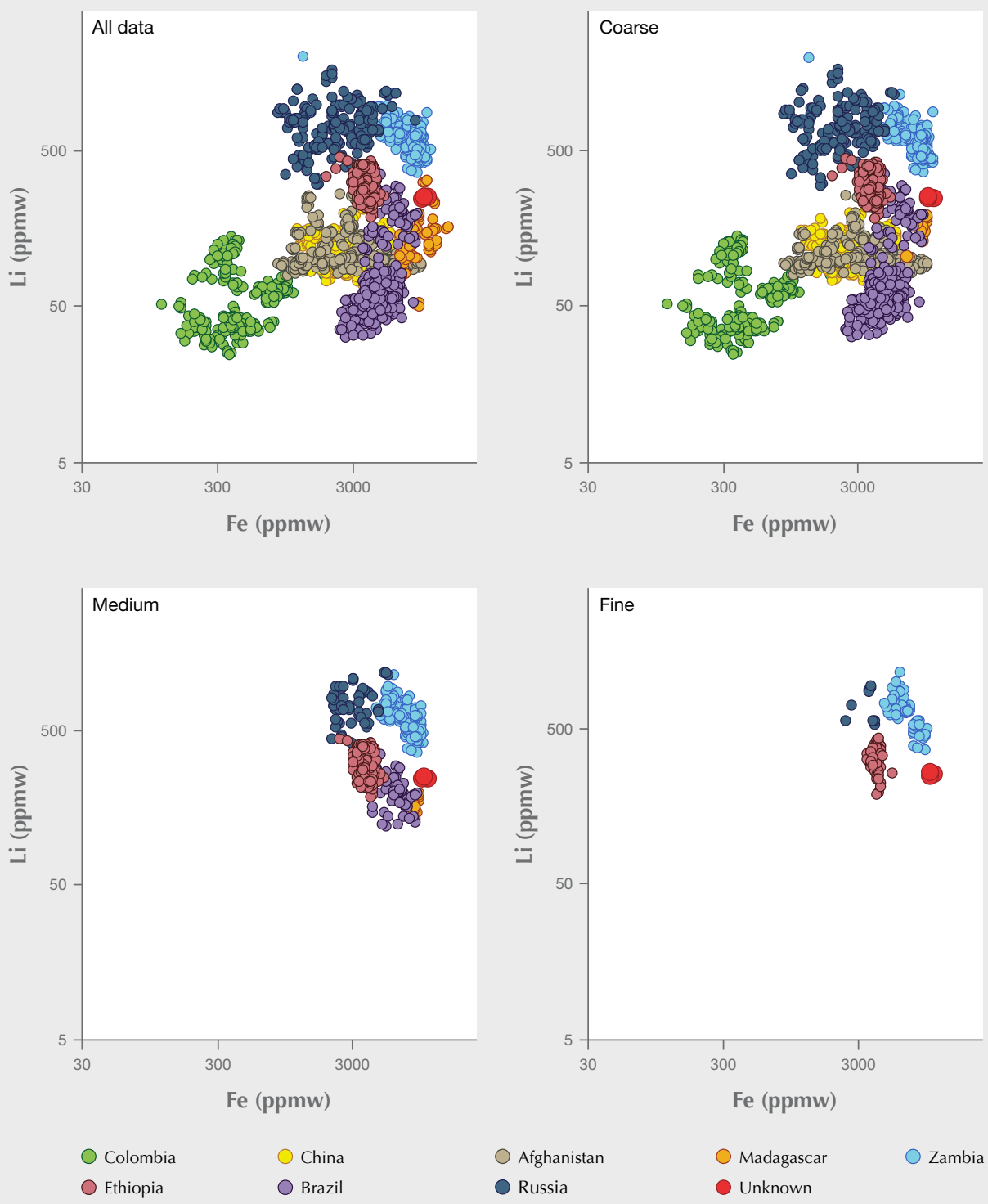

Figure CS 3-4. Trace element analysis of this unknown emerald (shown as the red circle) failed to conclusively match it with reference data of stones with known provenance. The ultimate origin call would be "inconclusive." The selective plotting method was used with coarse, medium, and fine filters. 


\section{CASE Study 4: ZAMBIAN EMERALD}

In this case study we examine the 1.04 ct stepcut emerald shown in figure CS 4-1. The UVVis-NIR absorption spectrum shows a significant rise beyond $700 \mathrm{~nm}$, leading to a large peak in the near-infrared region (figure CS 4-2). This allows clear assignment of this stone to the schist-related emerald group. Hence, the main geographic origins to consider are Zambia, Brazil, Russia, Ethiopia, and Madagascar. Microscopic examination shows abundant rectangular, blocky fluid inclusions (figure CS 4-3), an inclusion scene consistent with most schisthosted emeralds. However, the observation of such inclusions alone cannot lead to an accurate origin call. To finalize the origin determination, we need accurate trace element analysis. Figure CS 4-4 shows representative trace element plots from LA-ICP-MS measurements. Use of the selective plotting method demonstrates a clear correlation with Zambian emeralds from GIA's colored stone reference collection. Along with the spectroscopic and inclusion data, this allows a confident conclusion of Zambian origin.

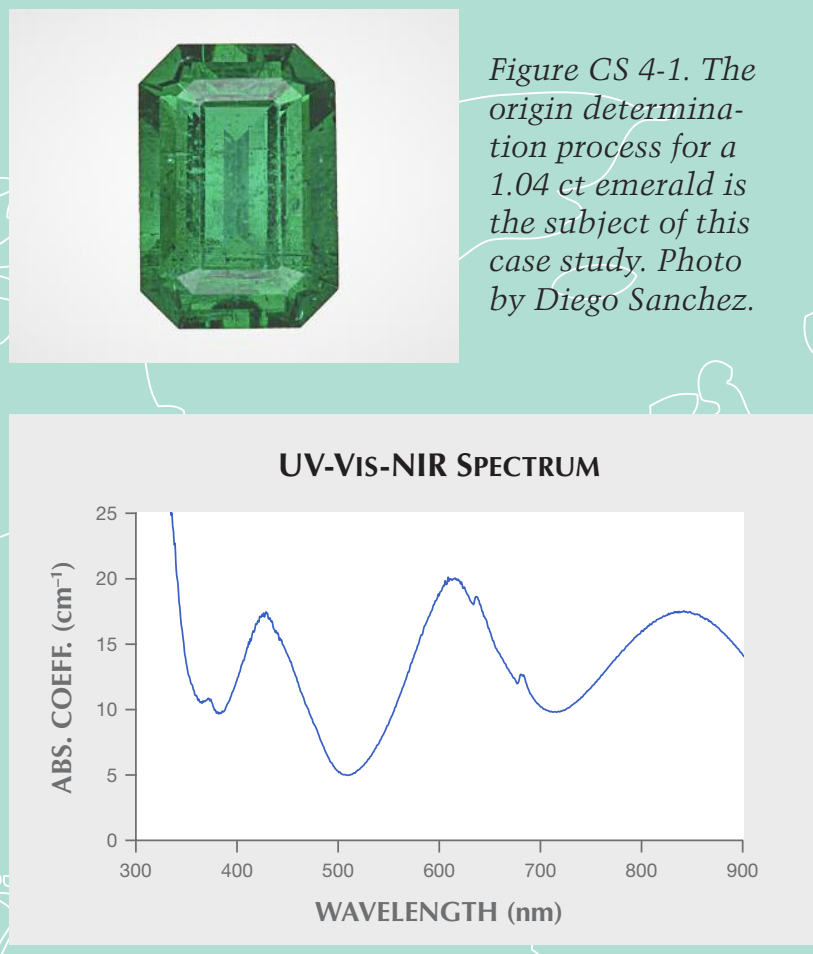

Figure CS 4-2. UV-Vis-NIR absorption spectroscopy provides evidence of a schist-hosted emerald that did not originate in Colombia.

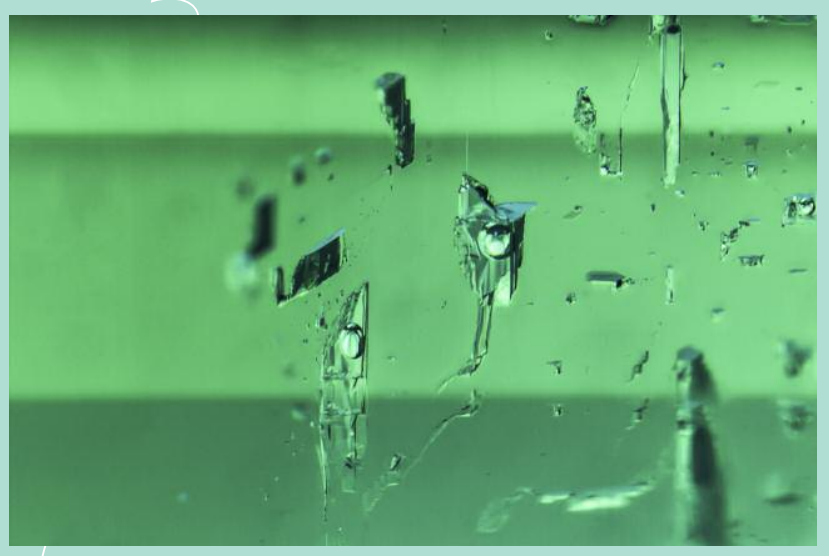

Figure CS 4-3. Blocky fluid inclusions point to a schist-related emerald deposit, indicating an origin of Zambia, Ethiopia, or Brazil. Photomicrograph by Nathan Renfro; field of view $1.89 \mathrm{~mm}$. 


\section{TRACE ELEMENT DiscriminATION}
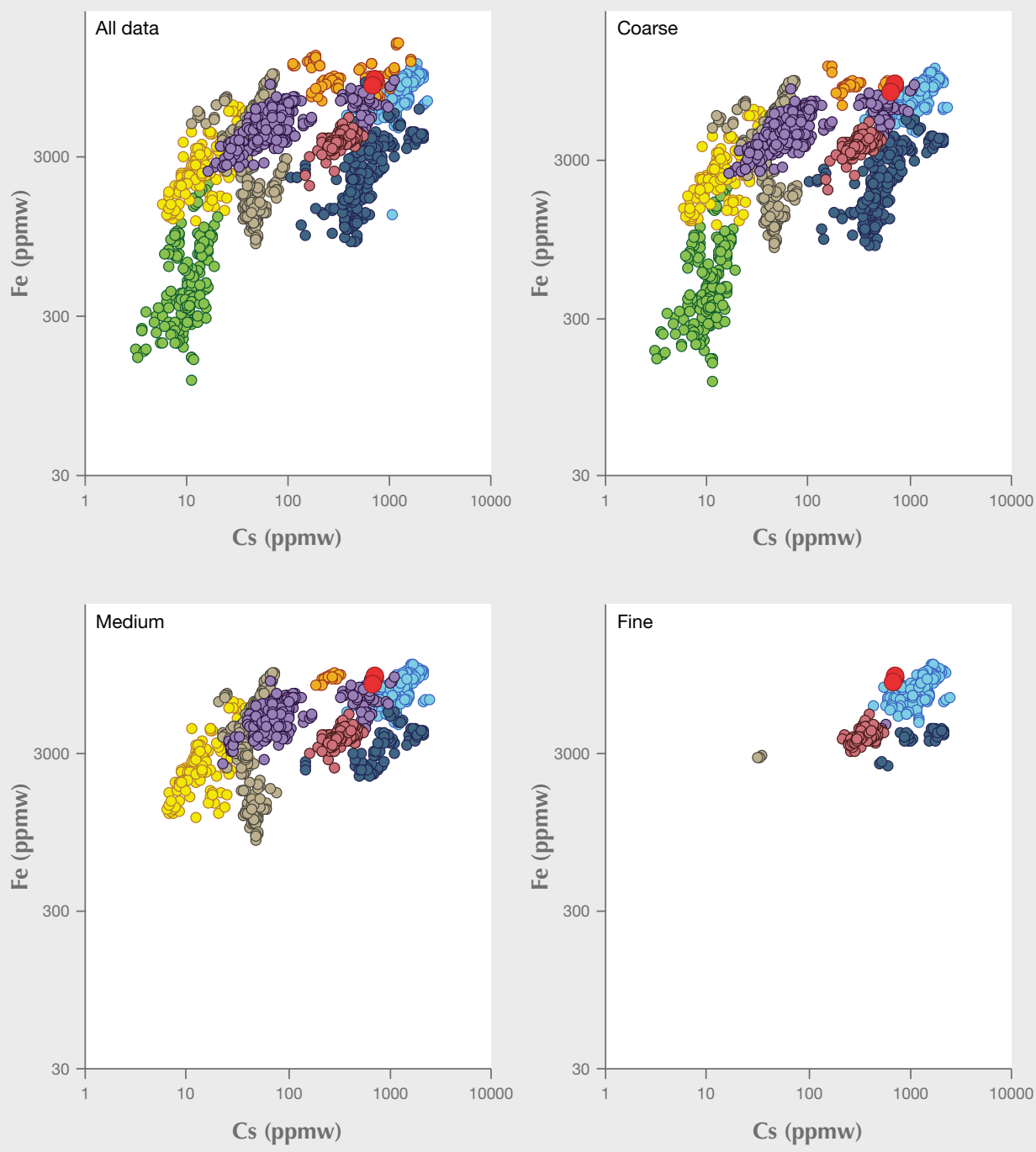
Colombia
China
Afghanistan
Madagascar
Zambia
Ethiopia
Brazil
Russia
Unknown

Figure CS 4-4. Trace element analysis provides conclusive evidence of Zambian origin. The selective plotting method was used with the coarse, medium, and fine filters. 


\section{ABOUT THE AUTHORS}

Ms. Saeseaw is senior manager of identification at GIA in Bangkok. Dr. Palke is a senior research scientist, Mr. Renfro is manager of colored stone identification, Mr. Sun is a research as sociate, and Mr. McClure is global director of colored stone services, at GIA's laboratory in Carlsbad, California.

\section{ACKNOWLEDGMENTS}

The authors would like to thank GIA colleagues in Bangkok and Carlsbad for their valuable assistance. We also thank James Day and Raquel Alonso-Perez and an anonymous reviewer for their thorough and helpful peer reviews which greatly strengthened this manuscript.

\section{REFERENCES}

Bosshart G. (1991) Emeralds from Colombia (Part 2). Journal of Gemmology, Vol. 22, No. 7, pp. 409-438.

Bowersox G., Snee L.W., Foord E.E., Seaf II R.R. (1991) Emeralds of the Panjshir Valley, Afghanistan. Ge G, Vol. 27, No. 1, pp. 26-39, http://dx.doi.org/10.5741/GEMS.27.1.26

Cassedanne J.P., Sauer D.A. (1984) The Santa Terezinha de Goiás emerald deposit. $G \uplus G$, Vol. 20, No. 1, pp. 4-13, http://dx.doi.org/10.5741/GEMS.20.1.4

Giuliani G., Groat L.A. (2019) Geology of corundum and emerald gem deposits: A review. GせG, Vol. 55, No. 4, pp. 464-489, http://dx.doi.org/10.5741/GEMS.55.4.464

Giuliani G., Cheilletz A., Dubessy J., Rodriguez C.T. (1993) Chemical composition of fluid inclusions in Colombian emerald deposits. Proceedings of the Eighth Quadrennial IAGOD Symposium, pp. 159-168.

Giuliani G., Chaussidon M., Schubnel H.-J., Piat D.H., RollionBard C., France-Lanord C., Giard D., de Narvaez D., Rondeau B. (2000) Oxygen isotopes and emerald trade routes since antiquity. Science, Vol. 287, No. 5453, pp. 631-633, http://dx.doi.org/10.1126/science.287.5453.631

Giuliani G., Groat L.A., Marshall D., Fallick A.E., Branquet Y. (2019) Emerald deposits: A review and enhanced classification. Minerals, Vol. 9, No. 2, p. 105, http://dx.doi.org/10.3390/ $\min 9020105$

Groat L.A., Giuliani G., Marshall D.D., Turner D.B. (2008) Emerald deposits and occurrences: A review. Ore Geology Reviews, Vol. 34, No. 1-2, pp. 87-112, http://dx.doi.org/10.1016/j.oregeorev.2007.09.003

Gübelin E.J., Koivula J.I. (2008) Photoatlas of Inclusions in Gemstones, Volume 3. Opinio Publishers, Basel, Switzerland, 672 pp.

Hänni H.A., Schwarz D., Fischer M. (1987) The emeralds of the Belmont mine, Minas Gerais, Brazil. Journal of Gemmology, Vol. 20, No. 7, pp. 446-456.

Marshall D., Pardieu V., Loughrey L., Jones P., Xue G. (2012) Con- ditions for emerald formation at Davdar, China: Fluid inclusion, trace element and stable isotope studies. Mineralogical Magazine, Vol. 76, No. 1, pp. 213-226, http://dx.doi.org/ 10.1180/minmag.2012.076.1.213

Palke A.C, Lawley F.J., Vertriest W., Wongrawang P., Katsurada Y. (2019a) The Russian emerald saga: The Mariinsky Priisk mine. InColor, No. 44, pp. 36-46.

Palke A.C., Saeseaw S., Renfro N.D., Sun Z., McClure S.F. (2019b) Geographic origin determination of blue sapphires. $G \uplus G$, Vol 55, No. 4, pp. 536-579, http://dx.doi.org/10.5741/GEMS. 55.4.536

Saeseaw S., Pardieu V., Sangsawong S. (2014) Three-phase inclusions in emerald and their impact on origin determination. $G \uplus) G$, Vol. 50, No. 2, pp. 114-132, http://dx.doi.org/10.5741/ GEMS.50.2.114

Vapnik Y., Moroz I., Roth M., Eliezri I. (2006) Formation of emeralds at pegmatite-ultramafic contacts based on fluid inclusions in Kianjavato emerald, Mananjary deposits, Madagascar. Min eralogical Magazine, Vol. 70, No. 2, pp. 141-158, http://dx.doi.org/10.1180/0026461067020320

Vertriest W., Wongrawang P. (2018) A gemological description of Ethiopian emeralds. InColor, No. 40, pp. 72-73.

Vertriest W., Palke A., Renfro N.D. (2019) Field gemology: Building a research collection and understanding the development of gem deposits. $G \uplus G$, Vol. 55, No. 4, pp. 490-511, http://dx.doi.org/10.5741/GEMS.55.4.490

Zwaan I.C., Seifert A.V., Vrana S., Laurs B.M., Anckar B., Simmons W.B., Falster A.U., Lustenhouwer W.J., Muhlmeister S., Koivula J.I., Garcia-Guillerminet H. (2005) Emeralds from the Kafubu area, Zambia. G»G, Vol. 41, No. 2, pp. 116-148, http://dx.doi.org/10.5741/GEMS.41.2.116

Zwaan J.C., Jacob D.E., Hager T., Cavalcanti M.T.O., Kanis J. (2012) Emeralds from the Fazenda Bonfim region, Rio Grande do Norte, Brazil. $G \uplus G$, Vol. 48, No. 1, pp. 2-17, http://dx.doi.org/10.5741/GEMS.48.1.2 